\title{
MONEY MATTERS
}

Mitigating risk to spark private investments in energy efficiency 
The International Energy Agency (IEA), an autonomous agency, was established in November 1974. Its mandate is two-fold: to promote energy security amongst its member countries through collective response to physical disruptions in oil supply and to advise member countries on sound energy policy.

The IEA carries out a comprehensive programme of energy co-operation among 28 advanced economies, each of which is obliged to hold oil stocks equivalent to 90 days of its net imports. The Agency aims to:

- Secure member countries' access to reliable and ample supplies of all forms of energy; in particular, through maintaining effective emergency response capabilities in case of oil supply disruptions.

- Promote sustainable energy policies that spur economic growth and environmental protection in a global context - particularly in terms of reducing greenhouse-gas emissions that contribute to climate change.

- Improve transparency of international markets through collection and analysis of energy data.

- Support global collaboration on energy technology to secure future energy supplies and mitigate their environmental impact, including through improved energy

efficiency and development and deployment of low-carbon technologies.

- Find solutions to global energy challenges through engagement and dialogue with non-member countries, industry, international organisations and other stakeholders.

IEA member countries:

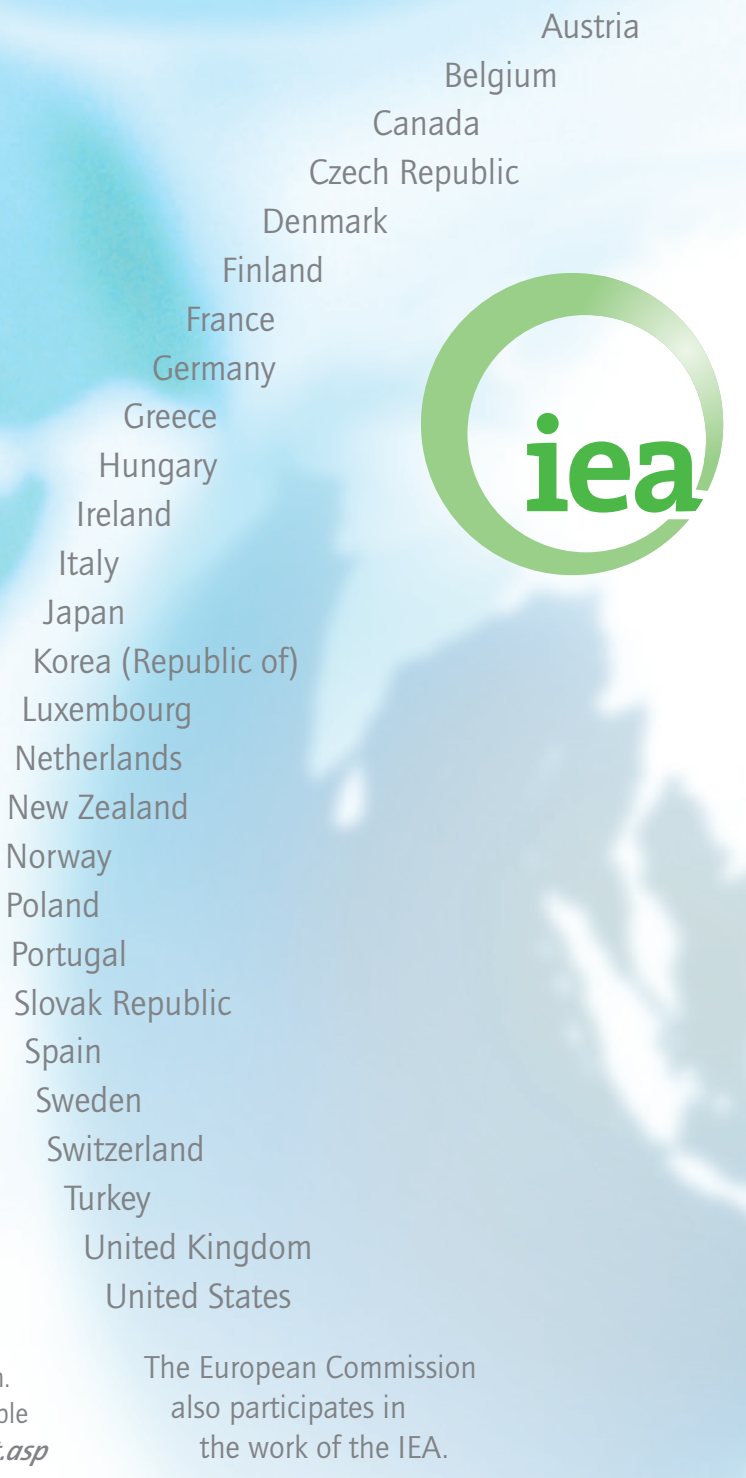

\section{(c) OECD/IEA, 2010 \\ International Energy Agency \\ 9 rue de la Fédération \\ 75739 Paris Cedex 15, France}

Please note that this publication is subject to specific restrictions that limit its use and distribution. The terms and conditions are available online at www.iea.org/about/copyright.asp
International Energy Agency

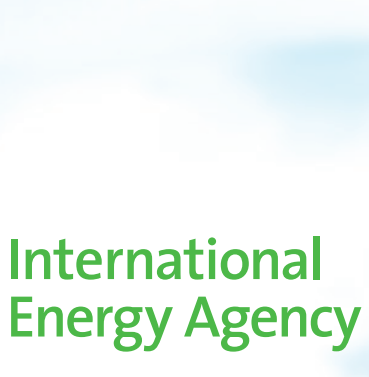




\section{MONEY MATTERS}

\section{Mitigating risk to spark private investments in energy efficiency}

This information paper was prepared for the Energy Efficiency Working Party. It was drafted by the Energy Efficiency and Environment Division, the Energy Efficiency Unit. This paper reflects the views of the International Energy Agency (IEA) Secretariat, but does not necessarily reflect those of individual IEA member countries. For further information, please contact philippine.detserclaes@iea.org 



\section{Acknowledgments}

This report was written by Philippine de T'Serclaes, Senior Finance Policy Analyst in the Energy Efficiency and Environment Division of the IEA, under the supervision, mentoring and creative support of Dr. Nigel Jollands, Head of the Energy Efficiency Unit, and Dr. Richard Bradley, Head of the Energy Efficiency and Environment Division of the IEA.

The author thanks her IEA colleagues Dr. Grayson Heffner, Richard Baron, Dr. Barbara Buchner, Sara Moarif, Jenny Gell, Sara Pasquier, Jens Laustsen, Tom Kerr, Cecilia Tam, Jonathan Sinton, Dagmar Gracyk, Julie Jiang, Sun- Joo Ahn, as well as, Rebecca Gaghen, Osamu Yamanaka and Bo Diczfalusy, who provided comments, provocative thoughts, brainstorming time and insights throughout the writing of the paper. Further thanks go to the $\mathrm{ClO}$ team without whom the paper could not have seen the light of day.

The author is indebted to all the interviewees who graciously provided their time and accepted to share their knowledge of energy efficiency markets: Calvin $\mathrm{Xu}$, James Maguire, Duncan Ritchie, Dilip Limaye, Murray Ward, Erik Haites, Alan Miller, Miles Stump, Thomas Pellerin, Hillary McMahon, Deborah Seligsohn, Ian Temperton, Rupert Edwards, Gemma Hunt, Ben Caldecott, Nick Robbins, Terry McCallion, Andreas Bierman, Fani Kallianou, Bernard Jamet, Murray Ward, Kirsty Hamilton, Eric Usher, Satish Kumar, Tom Dressden, Pierre Langlois, Yongqian Liu, Yu Cong, Ralph Sims, John MacLean, Jean Pascal Tranié, Jun Li, Leila Pourarkin, Ingrid Holmes, David Wheeler, Joanna Lewis, William Chandler, Mr. Jiang Kejun, Zhang Xiliang, Rajeev Palakshappa, Shabnam Bassi, Vivek Mehra, Dr. Frederic Brodach, Dr. Prasert, Sabine Miltner, Michael Liebreich, Michael Schneider, Manuel Flam, Arnaud Berger, Céline Kauffman, Will Blyth.

Thanks should also be extended to Tom Bastin, Martin Devine and the UK Government for the financial support which made the original research of this paper possible.

Marilyn Smith, Janine Treves and Eleanor Grammatikas (IEA) helped edit this document. Delphine Grandrieux, Anne Mayne and Corinne Hayworth (IEA) helped with the laying out of the paper. 



\section{Table of contents}

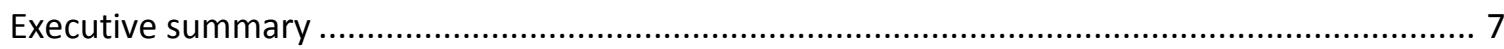

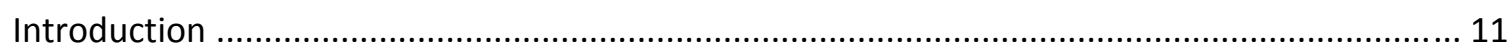

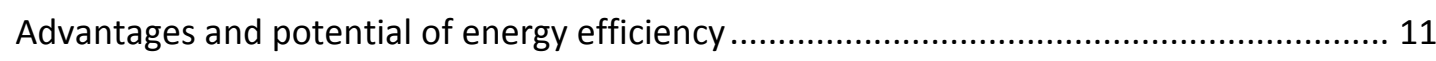

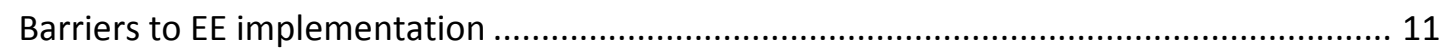

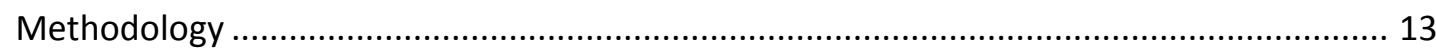

SECTION 1: Why is financing energy efficiency a challenge? A missed market opportunity ....... 15

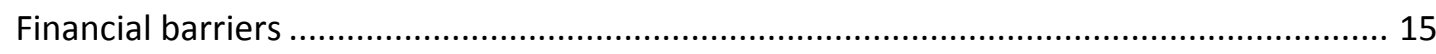

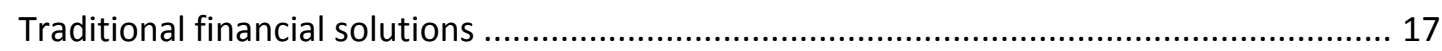

Risks associated with EE projects ................................................................................ 19

Challenges of local administrative and financial structures in China and India .................... 23

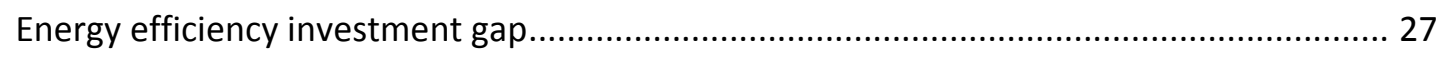

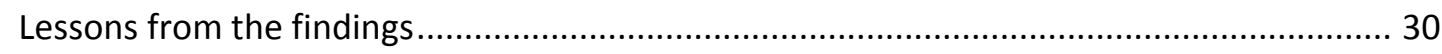

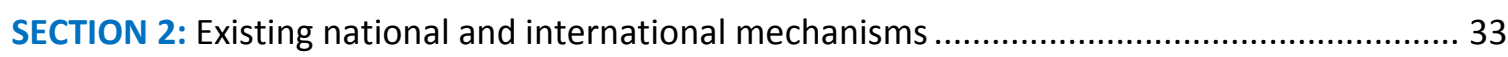

Case study 1 - Contingency financing: the IFC CHUEE programme in China ........................ 34

Case study 2 - Training and capacity programmes: cluster financing in India....................... 37

Case study 3 - Public/private partnerships: the Thailand revolving fund and the development

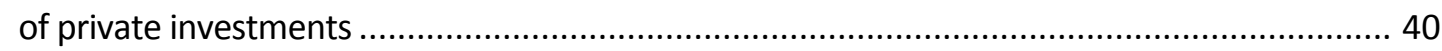

Case study 4 - International mechanisms: are they contributing to risk mitigation?

The case of CDM and its lessons for EE financing ................................................................ 43

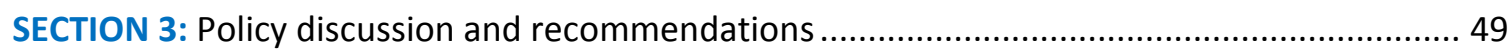

The role of the private sector: seizing business opportunity through creative financing..... 49

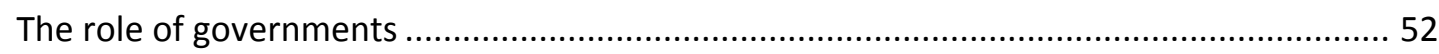

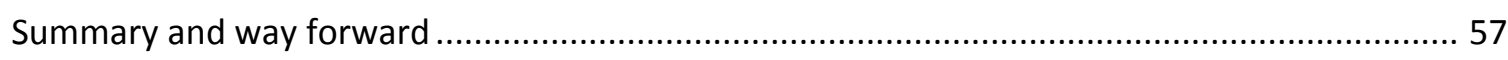

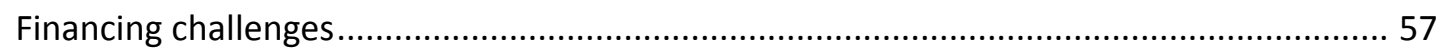

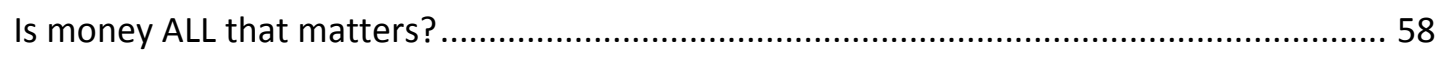

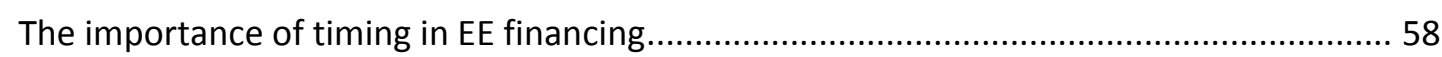

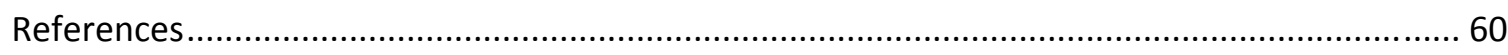

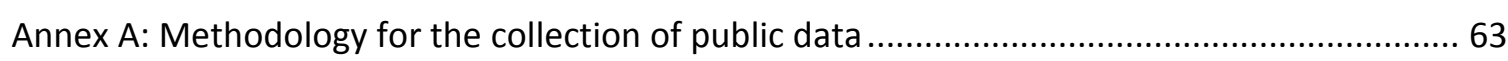

Annex B: Establishing public/private partnerships: ESCO market development in China and India .. 64

Annex C: Questionnaire sent to banks and participating institutions ........................................... 68

\section{List of figures, tables and boxes}

Figure 1: Barriers preventing higher energy efficiency implementation .................................... 13

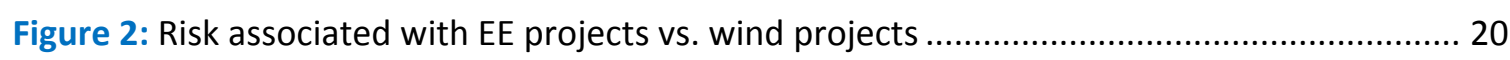

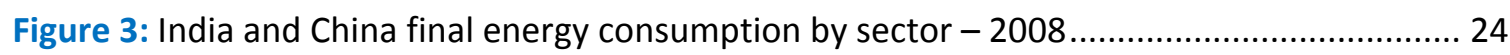

Figure 4: Total final consumption by fuel by sector for India ................................................ 25 
Figure 5: Energy Efficiency commitments by WB, ADB, EBRD and IADB 2000/2009 ................28

Figure 6: New investment worldwide by financing type efficiency and power storage ............. 29

Figure 7: New VC/PE investment worldwide by sector efficiency and power storage................ 30

Figure 8: Factors contributing to high risk perception and tools to help address the issue........ 33

Figure 9: The organisation of an IFC/GEF guarantee programme ...................................... 34

Figure 10: Cluster lending approach adopted in India ................................................... 38

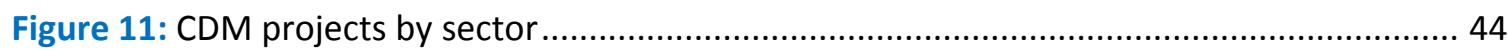

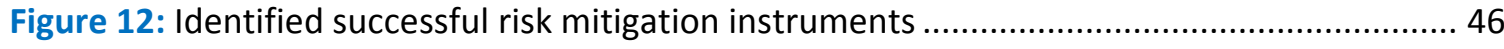

Figure 13: Triggering a virtuous circle of sustainable EE investments ..................................49

Table 1: Contract Enforcement: Brazil, China, and India Compared to Canada and the United States .23

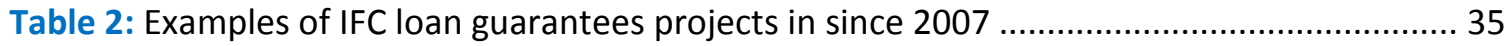

Table 3: Overall energy savings from the revolving fund phase 1 and phase $2 \ldots \ldots \ldots \ldots \ldots \ldots \ldots . . . . . . . . .41$

Table 4: Energy Efficiency measures implemented in the first phase of the project ................ 41

Box 1: The International Protocol for Monitoring and Verification (IPMVP)........................... 16

Box 2: Risk sharing guarantees in China with Industrial Bank ................................................ 35 


\section{Executive summary}

Scaling-up investment in energy efficiency is essential to achieving a sustainable energy future. Despite energy efficiency's recognised advantages as a bankable investment with immense climate change mitigation benefits, most of the energy efficiency (EE) potential remains untapped and the investment gap to achieve climate goals is tremendous. This report seeks to improve understanding as to why this is so, and what can be done about it.

Governments are committing large sums of money towards the mitigation of greenhouse gases through energy efficiency, but these are not nearly sufficient to address the EE investment gap. The Clean Technology Fund (CTF), for instance, provides a one-time infusion of USD 4.9 billion $^{1}$ towards emissions mitigation. However, these public investments are small compared with the projected investment needs - over USD 299.4 billion per year up to 2030 to reach the 450 scenario. $^{2}$ The United Nations Framework Convention on Climate Change (UNFCCC) estimates that over $86 \%$ of those investments should be covered through private investments. To date, however, private investment levels remain low. The Clean Development Mechanism (CDM) for instance - the official UNFCCC recognised channel for private investments in emerging economies' clean energy - amounted to only USD 67 billion of investments over a tenyear period - among which USD7.6 billion went to energy efficiency projects (UNEP/Risoe, 2010). This is equivalent to an average USD 760 million yearly, which is far from the estimated annual needs of USD 299.4 billion.

This study analyses the barriers to scaling-up private investments in energy efficiency and recommends concrete policies that can help close the EE investment gap by involving the private sector. The report focuses on barriers faced by investors and project developers looking to finance EE projects. More specifically, it analyses the impact of risks - actual and perceived associated with EE projects. Much has been written about the many barriers to energyefficiency investments, including market organisation, price distortions, split incentives, lack of information, transaction costs, institutional biases, product availability, regulatory policy, and others. ${ }^{3}$ This report does not delve into the full array of these barriers. Instead, it focuses on the financial and risk barriers.

The IEA undertook this study because there is relatively little literature that analyses the observed EE investment gap from a risk perception framework. For example, Financing Energy Efficiency (Taylor et al., 2008) provides an extensive treatment of suggested policies and structures in place to facilitate the financing of EE projects. However, there is little treatment of how the risks perceived to be associated with energy efficiency projects affect investment decisions, or why current mechanisms fail to address risk perception in project selection.

We hope this report contributes to unravelling the riddle of unrealised EE potential. Our shorthand for thinking about the problem forms the title to this report: does only money matter, or are there other factors affecting the apparent shortfall in EE investment? Key research questions posed include: How should public money be spent not only to maximise

\footnotetext{
${ }^{1}$ As of 30 September 2009; see http://www.climatefundsupdate.org/listing/clean-technology-fund

${ }^{2}$ Among which USD 17.8 billion for the building sector alone. Considering the WEO data of USD 2.55 trillion for the building sector and USD 3.1 trillion for other major economies, and assuming the ratio allocated to the building sector across region one estimates that USD 713 billion should be spent in the building sector in other major economies from 2010 to 2030. Hence, an estimated USD 17.8 billion /year should be spent from 2010 to 2020, while USD 53.5 billion should be spent from 2020 to 2030.

${ }^{3}$ See for instance Mind the Gap (IEA/OECD, 2007a).
} 
energy efficiency but also to trigger sustainable private-sector investment in energy efficiency? Do the low levels of EE investment result from a lack of financing, or is more complex decisionmaking behaviour at play? What do business and asset owners (and households) really consider in deciding whether or not to invest in an energy efficiency asset with apparently high returns? Observed incongruity between paper assessment and physical results raises the question of whether EE investments are about more money - public or private - being made available or whether other factors such as risk perception and project complexity are at play.

Evidence from this study suggests that targeting risk perception of investors through financial and other instruments could lead to scaled-up EE investments. We focus on emerging economies because most of the new EE investments required will be in China, India, and other emerging G20 countries. However, the investment barriers analysed and the policies recommended apply to both the developed and the developing world. Figure 1 graphically summarises our view of risk perception as the principal barrier to private EE investments. Key factors contributing to the perception that EE investments are riskier than other investments include (i) the intangible nature of energy efficiency, as its 'output' cannot be directly measured; (ii) the added complexity that energy efficiency sometimes brings to operations in buildings or factories; and (iii) costs associated with additional details of preparation and implementation, plus the scale of EE projects relative to other investments.

The elusiveness of EE benefits seems to be a significant drawback to potential investors. Contrary to other investments, energy efficiency cannot be directly measured in terms of incremental physical production. Rather, it is measured as a savings or decrement against a baseline of consumption or expense. The result is perceived complexity, which manifests itself through requirements for monitoring and verification (M\&V) to confirm the savings. Another factor contributing to the perception of energy efficiency as complex is the need for more advanced systems, processes, and even work practices embedded within EE solutions. For example, industrial managers often express concern about production down-times to install $\mathrm{EE}$ solutions. Some energy efficient devices (e.g. variable speed drives) may be more susceptible to voltage or frequency fluctuations on the grid. Energy efficient devices moreover often involve new technology with low operating experience. The highly technical realities underlying such investments result in investors demanding an implicitly higher rate of return to offset the perceived higher risk of energy efficiency projects. Finally, a perception of high transaction costs can emerge because of the small size of EE projects relative to other projects. These factors often have a reinforcing effect; the extra requirements for $M \& V$ or complicated shared savings contracts give rise to the perception of high preparation costs relative to savings.

Case studies and data gathered for this study suggest that policies, both financial and nonfinancial, exist to overcome the perceived higher risk associated with EE investments. Three policies in particular - risk guarantees, training and education, and increased public-private sector collaboration - have proven both effective and complementary. Contingency financing, for instance, provides an additional amount of cash to be spent if necessary. It can take many forms and most commonly that of a safety cushion or a direct cash injection as an equity stake. Increased public/private collaboration can also contribute to investment risk-hedging and confidence-building in investors. Training and education, including data and information sharing, serves to increase capacity building among investors and lenders, especially in emerging economies. Evidence similarly suggests that EE stakeholders are looking for increased guidance from government before scaling-up private investment in energy efficiency. 
Based on this evidence, the study makes four recommendations:

- Governments should increase data gathering, information sharing and training, including a platform for continuous public-private dialogue. The study calls for the creation of an Energy Efficiency Action Network (EEFAN); ${ }^{4}$ an international platform to enable regular cooperation and information sharing between the public and private sectors.

- Policy makers should focus on tools that reduce the perceived risk of EE projects. Financial instruments that guarantee EE projects address such risk perception. In the short term, this calls for the adequate disbursement of guarantee resources by the public sector through loan guarantee programmes (LGPs). Evidence from the case studies in China show that this form of contingency financing can help leverage private money up to four times the amount of public money invested.

- Governments should pursue the implementation of an international monitoring and evaluation protocol. Governments should continue their efforts to harmonise international $\mathrm{M} \& \mathrm{~V}$ protocol in an attempt to decrease risk perception and actual risks of EE projects. Maintaining a contingent financing facility is administratively costly even if the facility never disburses. In the longer term, the need for increased certainty through financial instruments could be replaced by the establishment of an international M\&V protocol which would create firm expectations for end-use energy efficient technologies. Provided such a framework is backed up by relevant stakeholders, it would allow the safe translation of uncertain technological potentials into certain investment streams of benefits.

- Finally, more work is needed to determine the best combination of financial and other instruments (such as training, education, capacity building or awareness building) for reducing high levels of perceived risk. Such work could develop a more programmatic approach to which combinations and sequences of financial instruments, public/private partnerships, and capacity building provide the best leveraging of private investment in the most cost-effective way.

\footnotetext{
${ }^{4}$ More details on this proposal are provided throughout the study.
} 



\section{Introduction}

The IEA's World Energy Outlook 2009 (IEA, 2009) estimates that reaching a 450 parts per million (450 Scenario) of carbon dioxide $\left(\mathrm{CO}_{2}\right)$ goal by $2030^{5}$ will require USD 10.5 trillion of new investments in the energy sector alone, of which an estimated USD 525 billion for energy efficiency (EE) improvements. ${ }^{6}$ Much of this investment will be net negative; the economic returns will more than offset the EE investment cost over the economic life of the assets. Despite energy efficiency's recognised advantages as a bankable investment with immense climate change mitigation benefits, economic advantages and positive impacts for energy security, most of the EE potential remains untapped and the investment gap in the 450 Scenario is tremendous. This report seeks to improve the understanding of this gap, and what can be done about it.

\section{Advantages and potential of energy efficiency}

Energy efficiency leads to more energy services - such as production, transport and warmth per unit of energy used (e.g. coal, gas and electricity). The many benefits of EE improvements increased energy security, reduced energy costs, cost-effectiveness and environmental benefits - have been described in detail elsewhere. The WEO 2009 estimates that over $57 \%$ of the energy mix to move the world towards a 450 scenario could be reached through the introduction of existing EE technologies. IEA analysis also estimates that by implementing its $25 \mathrm{EE}$ recommendations globally without delay, over $8.2 \mathrm{GT}$ of $\mathrm{CO}_{2}$ emissions could be abated yearly by 2030 (IEA, 2008b).

The buildings sector, for instance, currently responsible for close to $30 \%$ of today's world energy consumption, is a repository of untapped efficiency potential. This efficiency potential should be an attractive investment opportunity, as energy efficiency measures in the buildings sector generally have net-negative cost abatement opportunities, albeit with higher upfront costs that require additional financing. The estimated savings from the complete implementation of the IEA building recommendations are an annual 31.28 exajoules (EJ) by 2030 (IEA, 2008a). Similar savings could be achieved in transport, appliances and other sectors. In addition, the 25 IEA recommendations cover a range of measures across seven activity sectors, providing recommendations for appliances, equipment and lighting. It is estimated that these could save an additional annual savings of 21 EJ by 2030 (IEA, 2008a).

\section{Barriers to EE implementation}

Although EE technologies are commercially available and financially beneficial, consumers continue to use and purchase less efficient technologies (IEA, 2003; IEA 2010). Why then do consumers and investors shy away from paying a little more for the energy efficient alternative? Part of the problem is that saved energy is hard to see and harder to measure. Energy-saving technologies may look and outwardly perform just as inefficient ones, so consumers need help in making informed purchase decisions. The elusive nature of energy efficiency benefits can

\footnotetext{
${ }^{5}$ This number has been defined by the Intergovernmental Panel on Climate Change (IPCC) as necessary to limit global temperature increase to 2 degrees and constrain the impact of climate change.

${ }^{6}$ Based on WEO 2009 results, energy efficiency should represent $57 \%$ of the energy mix to move the world towards the 450 ppm scenario.
} 
make such investments harder to finance. Energy consumption is also deeply rooted in the economic activities in which the consumption takes place. These economic activities are, in turn, governed by embedded incentive structures, consumer behaviour, rules and regulations, infrastructure design and construction practices, investment decision making and even cultural considerations. All of these factors combine to form the market barriers that contribute to less than optimal use of EE technologies in existing buildings, homes and factories.

Technical and availability barriers occur in three situations: when there is a lack of affordable and available energy efficient technology suitable to local conditions; when there is insufficient local capacity to identify, develop, implement, and maintain EE investments; or when there is no distribution or delivery network to get energy efficient goods to consumers. Regulatory policy can be a major barrier, notably when the profitability of energy providers relies on energy sales, thus creating a disincentive to participate in supporting or delivering EE improvements to customers. Other regulatory barriers occur when there is a lack of capacity to consider, develop or enforce minimum energy performance standards or codes, when prices are set below marginal costs of service, or when there is uncertainty on recovery of EE programme costs.

An important subset of market barriers recognised by energy policy analysts are market failures (IEA, 2007a). Market failures include principal agent (PA) problems, and insufficient information and externalities. ${ }^{7}$ However, there are also other obstacles such as technical difficulties, institutional biases and regulatory failures which create problems to EE implementation.

Information failure is another obstacle to EE implementation. It occurs at different stages of the $E E$ chain. Actors tend not to know or understand the advantages of EE technologies in the first place, reflecting a lack of training and know-how (IEA, 2007a). Split incentives - such as the PA problems - have a preponderant impact on the building sector. Split incentives refer to situations where a person investing in energy efficiency improvement does not reap the corresponding financial benefits and as such has no incentive to make it happen. Mind the Gap (IEA, 2007a) quantifies this failure as amounting to $85 \%$ of the annual energy use of a country the size of Spain. ${ }^{8}$ Regulatory barriers can also be an obstacle when the price structures encourage utilities to deliver high amounts of energy, or when regulations do not promote the right standards, codes or services to encourage energy savings. Figure 1 below illustrates the array of barriers and obstacles facing the implementation of EE projects.

Much has been written about the many barriers to EE investments. This report does not delve into the full array of these barriers. Instead, it focuses on the barriers faced by investors and project developers looking to finance EE retrofit projects. Financial barriers, information failure and insulation of consumers from the price signal (e.g. as a result of high subsidisation) constitute obstacles to higher energy efficiency. A consequence of these barriers is that accessing capital for EE projects is difficult. Part I of the study establishes that the EE investment gap is still huge. More specifically, the report analyses the impact of risks - actual and perceived - associated with EE projects.

\footnotetext{
${ }^{7}$ Externalities are costs that are not reflected in energy prices, such as the environmental and health damages associated with energy production and use.

${ }^{8}$ For a more detailed discussion on the theoretical divides between market failures and market, barriers please refer to Mind the Gap (IEA, 2007a) Chapter 2.
} 


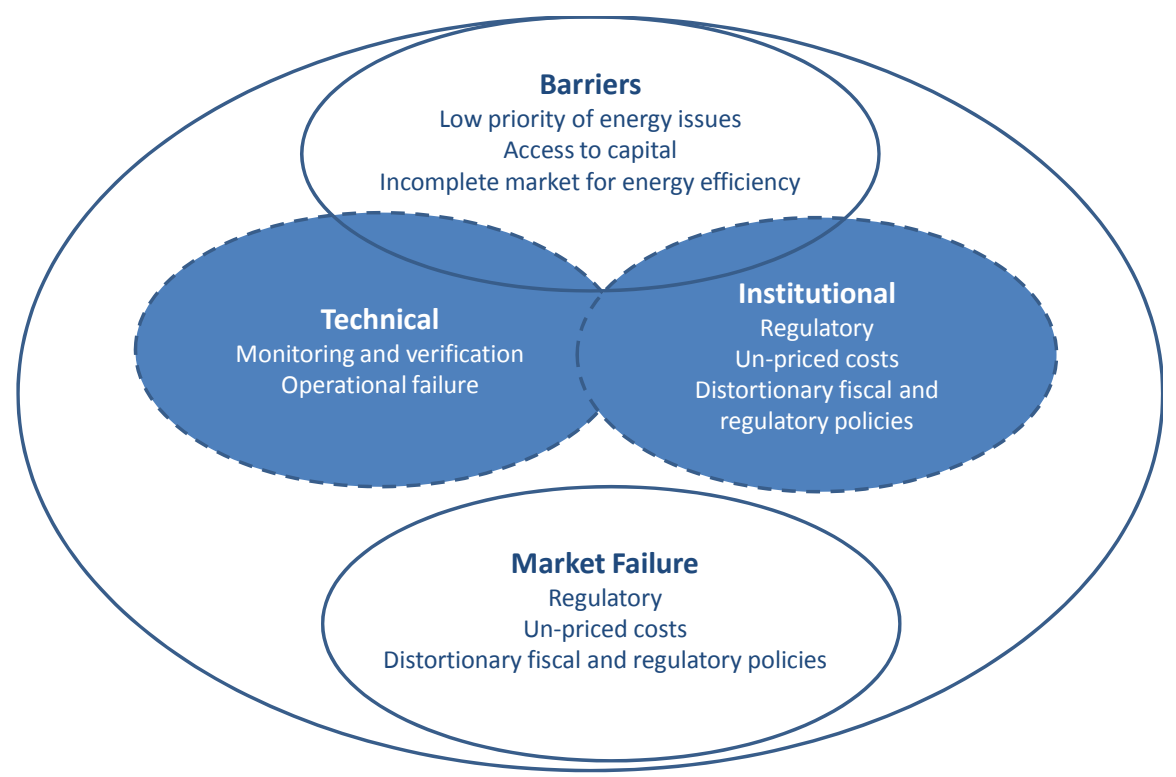

\section{Methodology}

This study sought new information and insights in the realities of the EE market that could help illuminate the barriers related to perceived risk of energy efficiency investments. Considering the limited literature available in EE financing within a risk perception framework, a survey and a series of semi-structured interviews were conducted.

A survey was circulated to major public and private financial institutions. ${ }^{9}$ The questions were designed to gauge the level of involvement - both direct and indirect - of each institution in the financing of $\mathrm{EE}$ projects in emerging economies. The survey and interviews focused on illustrations from India and China, with field studies in the two countries. Seventeen financial institutions out of the 25 returned the completed survey and agreed to provide insights into their activities. The institutions selected were determined by their level of activities in the studied regions. The results yielded insights into how EE markets operate, including the barriers to higher private sector participation. The results also provide a snapshot of trends and evolution of private sector investments into energy efficiency.

In addition to the survey, a round of semi-structured interviews followed. These were conducted in the United States, Europe, China and India. Over 45 projects and energy service companies (ESCO), managers, local and international commercial investment bankers, government officials, and independent consultants were interviewed. Overall, the interviews provided an opportunity to better understand both public and private financial institutions' perspective of the EE market opportunities and barriers. Personal interviews were conducted with representatives from the World Bank (WB), the International Finance Corporation (IFC), the European Bank for Reconstruction and Development (EBRD), as well as private financial institutions (JP Morgan, Deutsche Bank, Climate Change Capital etc.).

\footnotetext{
${ }^{9}$ For a participant list, please refer to Annex C.
} 
The results from the survey and interviews provide considerable insights into a range of issues concerning EE financing market realities. They allowed gauging the relative importance of different challenges facing $\mathrm{EE}$ financing, i.e. access to capital vs. risk, or others. The results uncover first-hand information and real-life barriers to EE implementation and feed into the analysis of the entire study.

Page | 14 Section 1 of the study overviews the main obstacles to EE financing. Section 2 analyses current international and local mechanisms which have helped overcome barriers to EE investments. Section 3 provides implications of these findings for the private sector and governments, and discusses possible ways forward in the financing of energy efficiency. 


\section{SECTION 1: Why is financing energy efficiency a challenge? A missed market opportunity}

The IEA undertook this study because there is relatively little literature that analyses the EE investment gap from a risk perception framework. For example, Financing Energy Efficiency (Taylor et al., 2008) provides an extensive treatment of suggested policies and structures in place to facilitate the financing of EE projects. However there is little treatment of how the risks perceived to be associated with energy efficiency projects affect investment decisions, nor why current mechanisms fail to address risk perception in project selection. We hope this report contributes to unravelling the riddle of unrealised EE potential by raising the question: does only money matter, or are there other factors affecting apparent shortfall in EE investments?

\section{Financial barriers}

Contrary to many investments, energy efficiency reduces costs rather than expanding production, making it more difficult to specify the benefits of investments. The absence of an internationally recognised protocol to measure, report and project energy savings in layman language, renders the quantification of energy efficiency difficult. Box 1 explains the challenges of implementing such a framework.

Although risk and uncertainty are important factors in any financial decision, EE investments involve multiple uncertainties that can be relatively difficult to quantify. Future revenue streams associated with energy efficiency improvements depend on numerous elements: the price of energy, the regulatory certainty, the evolution of subsidies, the credit risk of the country where the investment is being made, etc. The absence of a standardised benchmark for measurement of different technologies adds uncertainty to EE projects.

These uncertainties regarding future revenue streams make investors wary, and increase the difficulty for customers and project developers in accessing capital. It is often easier for investors to commit to improvements or new infrastructure projects that expand production rather than investments that deliver energy and cost savings (Taylor et al., 2008; Lovins, 2007).

As underlined by a London-based investor during an interview, "Governments need to make the left-hand side of the balance sheet tangible before the private sector can take care of the righthand side" (i.e. the money provision). This quote captures the essence of the EE financing challenge. The uncertainty around the real value of energy-saving potentials and the absence of physical assets to grasp in case of default mean that investors cannot adequately price the risk they are facing; thus, they turn to other projects. A consequence of this uncertainty is a possible inflated view of risks associated with EE projects. The issue of risk will be further elaborated in the next section.

Another obstacle to higher EE financing is the relatively small size of EE projects (de T'Serclaes, 2007; IEA, 2008a). EE projects are often perceived as too scattered, too small, and too technical - all for comparatively low returns. The higher upfront cost of EE technologies also constitutes a significant obstacle to their deployment. Although the technologies are economically sensible on a life-cycle cost analysis, they tend to be more expensive than their less efficient counterparts. This is of increased importance in emerging economies where a significant part of the population has difficulty affording bare necessities. This specificity of EE technologies is difficult to address as it touches directly on the behaviour of consumers when buying simple 
appliances. As one East Asian investor pointed out "the issue of scale is what is tripping up the banks right now; the commercial banks are not looking at this."

The lack of understanding of physical realities underlying EE savings, combined with the absence of adequate communication channels (e.g. tools that would allow the translation of these savings into financial revenue streams), helps explain why promoters and project developers

Page | 16 have difficulty accessing money for EE projects. Project managers' language is often too technical and in most cases they do not know how to address profit focused investors. In other words they do not "speak banker". This gap in communication underlines the need to establish adequate channels of communications between different stakeholders in the market (see Section 3).

These different challenges combine to form a high transaction cost of individual EE project. Investors end up considering EE projects as too much hassle for too little profit (Box 1). Having a clearer understanding of financial challenges to energy efficiency on a theoretical and practical level, the next section considers existing financial instruments and questions whether they can help EE financing.

\section{Box 1: The International Protocol for Monitoring and Verification (IPMVP)}

Although the International Protocol for Monitoring and Verification (IPMVP) was developed in 1997, it has yet to be accepted and recognised by all stakeholders, and perceived as an international reference. The IPMVP is still mainly viewed as an American protocol. The complexity of developing such a tool and getting it implemented worldwide reflects the challenges of energy efficiency projects: they rely on national methodologies which differ greatly from one another and which are very difficult to change. The means to measure the surface of a house for instance varies from one country to the other: one might consider that only surface until the windows should be included, while others might consider that only surface starting beyond the window and within a certain ceiling level will count. Similar concerns apply to appliances and different energy technologies: their certification relies on nationally entrenched habits which are difficult to shake. Such considerations explain the difficulty of applying an internationally recognised protocol. The main difference in calculation comes from three things: (i) the means to measure the surface; (ii) the amount of energy that you measure (i.e. all hours, every day, every month); and (iii) the level of details that you will provide. At the European Union level there are still over 30 different standards. In the section on lessons from current mechanisms, this study identifies the difficulties of establishing a common verification and certification protocol for the financing of projects.

At an industry level, electricity bills make up for a comparatively very low portion of the budget and as such will not be prioritised. Moreover, the frame of mind of an industry' executive is set on profit enhancing, not savings, which usually plays to the detriment of energy efficiency. The fact is that the scattered nature and the size of EE projects make it difficult to envisage a monitoring of every project independently. Monitoring and evaluation of energy savings is a particularly difficult element of energy efficiency programmes where quantification of baseline energy use is always challenging and poses a difficulty during implementation. Yet, the "development of a monitoring plan during the design stage, and adherence to it by implementers, with regular verification assisted by 3 rd parties, will ease the tracking of savings and provide basis for timely adjustments" (Sathaye et al., 2006). The implementation of a common language framework to report energy savings and convey their advantages to non-experts is however crucial to unlock private-sector investments. More will be said on the importance of establishing such a communications and reporting framework later in this study. 


\section{Traditional financial solutions}

Financing for energy projects mainly comes in two forms: debt and equity. In the case of debt financing, investors lend a certain amount of money on credit in exchange for repayment plus interest. In equity financing, investors lend a given amount of money in exchange for a stake in a project. These two forms can be channelled through a variety of financing tools.

\section{Balance sheet financing}

Customers or project developers frequently finance improvements or equipment purchases through commercial loans. In such transactions, the lender earns money through the amount of interest associated with the loan. The interest rate is in direct proportion to the risk associated with the project, i.e. the higher the risk, the higher the interest rate.

Lenders require information about borrowers' income capacity before making the loan. Lending on an unsecured asset (i.e. an asset that bears no security or collateral) will typically involve important risks, for which lenders will require high interest rates. By the same token, lending money to individuals, a variety of small projects, or to a number of firms, is usually associated with a higher risk than lending to another bank or a triple A grade Government. ${ }^{10}$ Lending under these conditions will require a higher interest rate and possibly additional collateral guarantees to secure the loan. The condition involves securing the loan based on assets listed in the balance sheet. The uncertainties surrounding projections of energy savings, as well as the intangible nature of negawatts (energy not consumed), means EE projects do not lend themselves well to traditional loan financing.

\section{Equity financing}

Equity financing is another means for project developers to access capital. In equity financing, investors provide cash to project developers in exchange for a stake in their project. The most common example of equity financing is private equity. In such deal structures, the investors will typically invest in a project for which he/she has secured an adequate medium-to long-term exit strategy that will be profitable. Such exit strategies include the reselling of the share through, for instance, an initial public offering (IPO).

The small size of the EE end-use projects again is a deterrent in this kind of deal structures, as small project are ill-suited for IPO deals. Lacking a clearly defined exit strategy, equity investors tend to shy away from financing EE projects. ${ }^{11}$

\section{Mezzanine financing}

Mezzanine financing is a hybrid form of financing that combines debt and equity financing. In most cases, debt will be ranked as a preferred equity share. This means that in case of default, it will be senior in priority only to preferred stocks. Mezzanine debt financing is thus riskier than traditional debt-financing but also more rewarding; it is associated with a higher yield.

\footnotetext{
${ }^{10}$ Governments as well as firms are graded by rating agencies (Standard \& Poors, Fitch, etc.).

${ }^{11}$ In the case of the development of a mature secondary market with proper exit strategies, one could easily imagine private stakeholders being increasingly active through private equity.
} 
Mezzanine financing also allows a lender to convert debt capital into ownership or equity interest in the company if the loan is not paid back on time and in full.

Mezzanine financing can be structured either as debt or equity (i.e. preferred stock). As such, it is more flexible than equity financing. This type of financing can be particularly useful for midsized enterprises that cannot access high yield markets due to high minimum size requirements.

Page | 18 However, issues of uncertainties around collaterals and problems identifying exit strategies still apply to mezzanine financing used for EE projects.

\section{Project finance ${ }^{12}$}

Project finance (PF), by contrast to balance sheet financing (loans, debt and equity), bases its collateral on a project's cash flow expectations, not on individuals or institutions' creditworthiness. It is off-balance sheet financing. A typical PF is divided between debt and equity financing. Debt is usually a conventional commercial bank loan to which a customer pays interest (i.e. thereby paying for the loan and the price of the debt). Lenders normally charge a pre-determined rate of interest that is set by adding an interest margin to the bank's standard inter-bank lending rate, which represents its income.

Customers who have strong balance sheets will not have to resort to PF. Gearing (the ratio of debt to equity) is much higher in project finance than in 'on-balance-sheet' financing. A division of $70 \%$ to $30 \%$ debt-to-equity ratio is common in project finance. An advantage of off-balancesheet financing is that banks are usually willing to extend the length of the project finance loans to almost 15 years (because they will have much more control over the project). The off-balance sheet structure of project finance could apply very well to EE financing that is based on potential revenues for EE savings. However, the small size of EE end-use projects is usually detrimental as PF deals have very high transaction and minimum ticket size of around USD 20 million. The heavy contracting at the basis of this deal structure explains the high transaction costs and minimum ticket size.

\section{Leasing}

The energy market's common way of dealing with initial cost barriers is leasing. Leasing is suited to situations where physical assets form the bulk of the expenditure (rather than labour services), and where use of the asset may be denied the ultimate owner in the event of default. Leasing is an off-balance sheet form of financing. There are two different kinds of leasing: operational and financial leases. The former generally concerns shorter-term leases, and is cancellable. The latter, by contrast, is typically non-cancellable and will transfer all the risk to the lessee. The transaction costs involved in leasing on a small scale would be high, relative to consumer credit, and there would be greater risk for the lender and higher cost for the borrower, in projects with a low component of physical assets. Hence, leasing is not an appropriate instrument in cases of end-use EE projects.

\footnotetext{
12 Examples of off-balance-sheet financing include joint ventures, research and development partnerships, and operating leases (rather than purchases of capital equipment). Operating leases are one of the most common forms of off-balance-sheet financing. In these cases, the asset itself is kept on the lessor balance sheet, and the lessee reports only the required rental expense for use of the asset. Generally Accepted Accounting Principles in the United States have set numerous rules for companies to follow in determining whether a lease should be capitalised (included on the balance sheet) or expensed.
} 
Applying traditional financial tools to the realities of energy efficiency proves to be difficult. The next section introduces additional barriers to EE financing: risks and the gap between actual and perceived risks.

\section{Contingent financing}

In contrast to the financing mechanisms described above, contingent financing represents money not included in the balance sheet. That sort of financing is usually a cushion buffer provision in case something goes sour in the process, or an extensive liability happens. Contingency financing is usually provisioned for such events as lawsuit settlements, provision for default payment, etc. In the case of EE financing, contingency financing can be a useful provision for capacity building as well as potential default, risk guarantee provision.

Contingent financing is attractive when there is uncertainty about the extent and existence of incremental costs. Instead of committing to a grant which may subsequently prove to have been unnecessary, contingent financing recognises the potential need for support but draws on public resources only when justified later, on the basis of actual rather than projected costs.

\section{Risks associated with EE projects}

The main risks faced by EE projects fall into five categories:

- Operational risk: describes the risk of a technology failure while in use;

- Technical/project risk: is a failure in the project implementation, any consumer change, or technical breakthrough during the implementation phase of the project;

- Monitoring risk: reflects uncertainty surrounding a local user's ability to monitor the implementation of a technology;

- Regulatory and institutional risk: refers to uncertainty on the reliability of policies in place or unpredictable, sudden changes in regulation;

- Financial risk: includes risks of losses due to price fluctuation of energy (i.e. electricity); interest rate movements, oil price volatility, as well as counterparty risk (the risk that the borrower will not be able to repay the banker).

Most of these risks can be handled through well-known management and financial tools. Intrinsic risks, such as failure in the systems or technologies, are controlled; external risks, such as volatility of a given resource price, can be hedged with appropriate risk-mitigation instruments. Figure 2 illustrates the differences in risk exposure of EE projects versus wind power projects. Wind is a useful comparison because although it is technology based, it offers tangible assets (e.g. physical structure) as a security guarantee, unlike energy efficiency.

As in all technology-based projects, EE projects run operational and technical risks - a risk that the technology fails while in use or that the technology under performs. EE projects are also subject to technical risk. In the case of wind technology, such risk is characterised by the variability of storms and wind occurrence, as well as the reduced output that can result from a damaged plant. In the case of EE projects, the challenge is twofold: the difficulty of measuring output (energy savings) and uncertainties surrounding a non-expert's capacity to properly implement EE technology. 
Figure 2: Risk associated with EE projects vs. wind projects

\begin{tabular}{|c|c|c|c|c|c|c|}
\hline \multicolumn{7}{|l|}{ Page | 20} \\
\hline & $\begin{array}{l}\text { Energy } \\
\text { Efficiency }\end{array}$ & $\begin{array}{l}\text {-Failure of } \\
\text { the } \\
\text { technology } \\
\text { while in use }\end{array}$ & $\begin{array}{l}\text {-Difficulty of } \\
\text { quantifying } \\
\text { energy } \\
\text { savings } \\
\text {-Uncertainty } \\
\text { on savings }\end{array}$ & $\begin{array}{l}\text { - Uncertainty of } \\
\text { person capacity } \\
\text { to implement } \\
\text { technology } \\
\text {-Cost of M\&V }\end{array}$ & $\begin{array}{l}\text { - Uncertaintyon } \\
\text { price of energy } \\
\text { - Uncertain } \\
\text { changes in } \\
\text { regulation }\end{array}$ & $\begin{array}{l}\text { - Uncertainty on } \\
\text { price of energy } \\
\text { - Counterparty } \\
\text { risk }\end{array}$ \\
\hline & Wind & $\begin{array}{l}\text {-Repairs to } \\
\text { offshore assets } \\
\text { will be } \\
\text { expensive } \\
\text { (money wise } \\
\text { and time wise) }\end{array}$ & $\begin{array}{l}\text {-Wind } \\
\text { variability and } \\
\text { storms can } \\
\text { reduce output } \\
\text { of damaged } \\
\text { plant }\end{array}$ & $\begin{array}{l}\text {-Important } \\
\text { costs of } \\
\text { monitoring } \\
\text { output }\end{array}$ & $\begin{array}{l}\text {-Renewable } \\
\text { feed-in tariff, } \\
\text { regulations } \\
\text { are subject } \\
\text { to change }\end{array}$ & $\begin{array}{l}\text {-Electricity and oil } \\
\text { price volatility, } \\
\text { currency exposure } \\
\& \text { counterparty } \\
\text { risk exposure }\end{array}$ \\
\hline
\end{tabular}

Other risks are found in the regulatory uncertainties surrounding the implementation of EE projects. The political context and regulatory consistency of the country where a given project is implemented will have a preponderant impact on the investor choice. Renewable projects, for instance, are often financed with the help of feed-in tariffs. Irregularities in the administration of such government help can deter many investors. More generally, known irregularities in the price governance of electricity, or energy can discourage capital providers from investing in energy efficiency projects. A sudden change in the price of electricity while the project is being implemented would affect its expected return on investments. The financial risk is also characterised by a risk of default in the counterparty.

Risk-management tools, such as insurance products, credit-enhancement facilities, hedging tools, loan guarantee programmes, can be implemented to tackle the variety of risks faced by EE projects. The price volatility of energy (e.g. oil or electricity) could be addressed through insurance mechanisms. Technical failures could be addressed through adequate contract exclusion. Uncertainty in the currency or institutional strength can also be addressed through the implementation of high interest rates. International public institutions such as the Multilateral Investment Guarantee Agency (MIGA) help mitigate such risks. The private market can also provide similar instruments, such as credit-enhancement facilities. The monitoring risk can be faced through appropriate capacity building, awareness raising and training. ${ }^{13}$

\section{The importance of perception (and information sharing)}

Appraising risk and developing appropriate risk-mitigation instruments is both an analytic and a subjective undertaking. Some risk-appraisal can be done objectively, (e.g. the performance indicator of a given technology, the regulations in place in a country at a given time, etc.), other elements will be more subjective, (e.g. the overall assessment of the situation or the interplay of the different issues at stake). In their groundbreaking article "Why study risk perception?" Slovic, Fischhoff and Lichtenstein (1982) underline many instances - and more specifically cases involving technology - where laypeople share an inaccurate perception of risk. For example

\footnotetext{
${ }^{13}$ Different hedging tools have been designed for these: futures, forwards, swaps and options.
} 
non-experts tend to associate much higher risks to toxic substances than actually exist. This subjectivity in risk perception is caused by a variety of informal, experiential factors called heuristics. Heuristics refer to behaviours, reflexes and view points which are deeply ingrained in codes of conduct and perceptions that are particularly hard to change and overcome. A specificity of these heuristics is their foundation on irrational intuitive behaviour, by contrast to reasoning or objectivity. As such they become even more difficult to influence and nudge.

The same phenomenon can happen with EE projects. Lacking the information and appropriate tools to translate the physical realities underlying energy savings, specific investors could overestimate the technical and operational risks (Box 1). Such perception would only be reinforced by a lack of information concerning successes of risk-mitigation instruments in certain $\mathrm{EE}$ projects, as well as adequate experience in this area. As a result, people would not resort to existing tools to mitigate the risk of EE projects. Studies show that the underperformance of some earlier EE technologies - such as compact fluorescent lamps (CFLs) - has left a lasting mark with consumers who remain wary of these technologies long after the risks of underperformance have been removed (Lefevre, de T'Serclaes \& Waide, 2006). The CFL example illustrates a case where the operational and technical risks are overblown based on inadequate information; the performance of more recently manufactured CFLs should be better broadcasted.

The uncertainty surrounding EE savings, reinforced by the absence of an internationally recognised monitoring and verification (M\&V) protocol, results in a perception that $\mathrm{EE}$ operational risks are high. As an investor puts it "having no physical assets to securitize, and no tangible guarantees in case of defaults, investors would much rather finance a renewable or other plant, whose risks can be quantified." The intangible nature of the left-hand side of the balance sheet in EE projects means that both operational and financial risks tend to be inflated by investors. The amount of effort currently required by investors to translate the physical realities of EE projects into monetary value is still too important to justify investors' involvement. An investor in Hong Kong repeatedly pointed out that banks were still reluctant to back up ESCOs because they had no "insurance against their credit risk."

Should these uncertainties be clarified however, the remaining risks could actually be hedged through existing risk-mitigation instruments. Commodity and derivative traders design tools to deal with risk and volatility on a daily basis. The secondary financial market offers various tools to handle the risks faced by EE projects. In the current situation however, these same traders cannot capture the financial opportunities of EE projects because they do not understand the physical realities of these projects. Without the creation of framework and/or protocol to translate the physical realities of energy savings into certainty in the investment revenue streams, the gap between financial institution's risk perception and the actual risks faced by EE projects will endure. As underlined by Mills et al. (2006), energy managers and investment decision-makers "simply do not speak the same language". As a consequence, investors fail to perceive the financial opportunity of EE projects, and instead still view EE projects as a physical necessity.

The persistently high operational and financial risks associated with EE projects constitute a major obstacle to the higher private-sector involvement. Although EE projects are indeed risky, current operational and financial risks associated with the projects could arguably be inflated compared to the track record of technologies and default case. As the next section illustrates, the context of emerging economies can introduce additional risks and difficulties to the financing of EE projects. 


\section{Additional risks specific to emerging economies}

Beyond the obstacles facing the financing of end-use EE projects, the economic, institutional and social realities of emerging and transitional countries can add difficulties.

\section{Page | 22 Sovereign risk}

Foreign investors consider risks associated with a country before investing. Credit ratings for countries under development are usually lower than those of developed countries. As such, investors consider these countries a more risky environment for their investments. Studies reveal that a given technology market in emerging economies needs to be more mature than the same technology market in a more developed economy. This is because investors give more weight to sovereignty risk in emerging markets than for those of developed countries. Emerging countries tend to score lower grades of investment from rating agencies.

\section{Institutional frailty: contract failure}

Institutional frailty and inconsistency are additional risks for foreign and national EE financing. The unfamiliarity of the sector means that investors are cautious of the risk-to-return ratio, which is not necessarily well balanced compared to other types of financing (Sathaye et al., 2005; Taylor et al., 2008). Interviews conducted with major stakeholders in the market underline the negative lasting consequences and image that the recent and sudden change in policy rules in the Indian ESCO market has had on investors. Moreover, previous mishaps in sudden regulatory changes - such as the 1996 change in India's regulation - keep investors wary of investing there again. ${ }^{14}$ This view was reinforced by a private equity fund manager involved in India. While regulatory changes also occur in developed countries, there is a perception among investors that the risks of sudden regulatory changes are higher in emerging economies than in developed countries. During the interviews, a specialist of the Indian market pointed out that sudden changes in governmental policy which happened in the past potentially discouraged business decisions. However, India's EE programs introduced in the last 10 years would reduce these types of uncertainty for EE investors.

Table 1 shows the contract enforcement in three major emerging economies (Brazil, China and India) compared to two developed countries (Canada and the United States) (Taylor et al., 2008). The data were collected in reference to (i) the number of procedures from the moment the plaintiff files a lawsuit in court until the moment of payment; (ii) the time in calendar days to resolve the dispute; (iii) the cost in court fees and attorney fees, where the use of attorney is mandatory or common, expressed as a percentage of the debt value; and (iv) the country's place in the league table rankings among the 175 countries rated in this measure. China and India rank 63rd and 173rd respectively on the world's 175 ranked countries for contract enforcement. The table further underlines the contrast with countries such as Canada or United States, which rank 6 th and 16 th respectively.

\footnotetext{
${ }^{14}$ This regulation refers to the amortization tax change in 1996, which may impact both EE business and the general financing environment in India. However, the extent of this policy change on today's EE business in India remains controversial.
} 
Table 1: Contract Enforcement: Brazil, China, and India Compared to Canada and the United States

\begin{tabular}{|lcccc|}
\hline Country & $\begin{array}{c}\text { Procedures } \\
\text { (number) }\end{array}$ & $\begin{array}{c}\text { Time } \\
\text { (days) }\end{array}$ & $\begin{array}{c}\text { Cost } \\
\text { (\% of debt) }\end{array}$ & $\begin{array}{c}\text { Rank } \\
\text { (of 175) }\end{array}$ \\
Brazil & 42 & 616 & 15.5 & 120 \\
China & 31 & 292 & 26.8 & 63 \\
India & 56 & 1420 & 35.7 & 173 \\
Canada & 17 & 346 & 12 & 16 \\
United States & 17 & 300 & 7.7 & 6 \\
\hline
\end{tabular}

Source: Taylor et. al, 2008

Contract enforcement is one among many other indicators of business stability and institutional frailty. In this context, it has an impact on ESCO managers' ability to access equity. ESCO models rely most of the time on energy performance contracting. As such it will be affected by uneven contract enforcement. ESCO managers interviewed in both countries emphasised their difficulty in accessing equity; banks and investors are wary of the actual performance and stability of ESCO revenues. This could be an indirect consequence of such contract enforcement frailty.

A lack of appropriate financial infrastructures to facilitate financial networking can be an issue. Taylor et al. (2008) underline that the most significant recurring obstacle to higher EE levels in emerging economies result from a lack of adequate institutions. Less specific to India and China, it concerns on the overall adequacy of emerging economies' environment for foreign investments, viewed as less enticing to investors due to a track record of failed deals. Moreover ESCO managers interviewed in both India and China underlined the importance of such institutional frailty in preventing their obtaining enough equity.

\section{Challenges of local administrative and financial structures in China and India}

Illustrations from India and China, two major emerging economies and big energy consumers, can help identify challenges common to other emerging economies. Although the difficulties and specific nature of the challenges will vary depending on the national context, the Indian and Chinese cases provide similarities in the financing challenge of EE projects in emerging economies.

Despite the economic, energy security and environmental advantages of energy efficiency, other aspects of social and economic development can take precedence over energy efficiency, which can fall at the bottom of policy maker's list of priorities. Such a standpoint is however evolving. The governments of India (GOI) and China have been setting very ambitious goals in EE improvements in the last five years.

The booming economic growth of both India and China has opened the way to significant untapped EE potentials. Figure 3 illustrates the current breakdown of Chinese and Indian final energy consumption by sector in 2008 . They underline that both the residential and industrial sectors represent close to $3 / 4^{\text {th }}$ of these countries' energy consumption. While the residential sector represents $41 \%$ of total final energy consumption in India, the industrial sector still makes up $28 \%$. In China the industrial sector represents $48 \%$ of total final energy consumption, while the residential represents $25 \%$. Transport also represents an important area of consumption with an $11 \%$ share in both countries. 

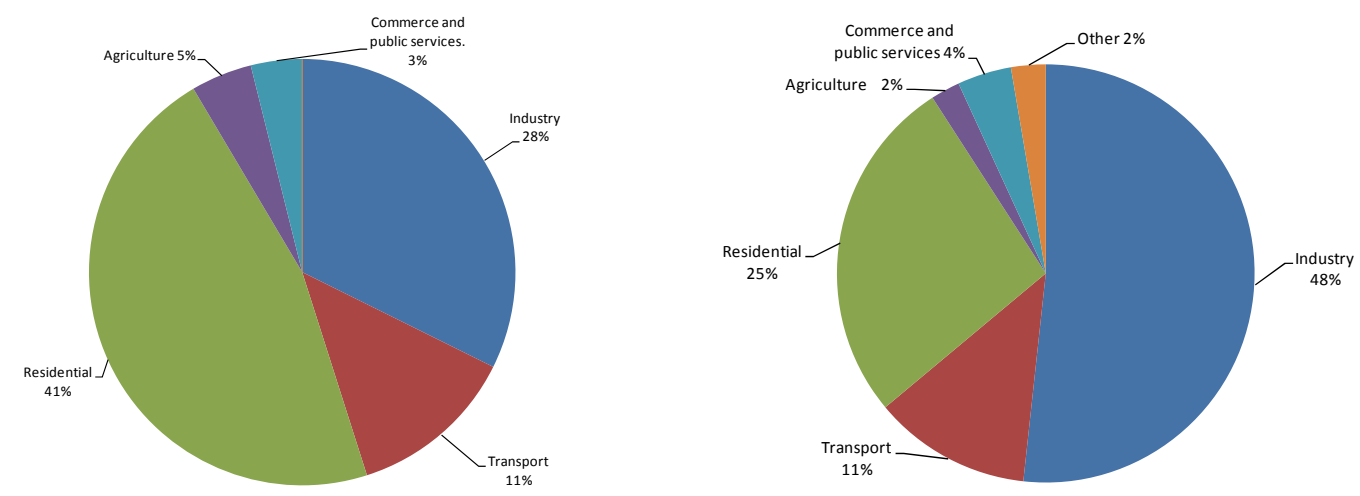

Source: IEA statistics, 2010

\section{China}

Energy efficiency has been a priority of China's government since the 1980s, when it first created new institutions and agencies to carry forward this work. In the past decade, an even greater emphasis on energy efficiency has emerged. China's $11^{\text {th }}$ Five-Year Plan (2006-2010) established a very ambitious target to improve the overall energy intensity of the economy, and this laid the foundation for strengthening existing and creating new sectoral policies, regulations, codes and standards, administrative measures, and capacity building to improve energy efficiency in all sectors.

One of the many consequences of China's growing economy has been a steep increase in its electricity demand. Those needs are mainly met through the country's coal reserves - the second biggest in the world after the United States. Coal is the main prime mover in China's power sector, providing over $80 \%$ of all electricity. While the average efficiency of China's fleet of coal-fired power plants is rapidly approaching that of OECD countries - both through new construction, including most of the world's new ultra-supercritical units, and a vigorous programme to close small, inefficient units - further gains are possible, both on the generation side and in transmission and distribution networks. To a certain extent, switching from coal- to gas-fired generation can help to improve power sector efficiency, as it can in numerous applications in industry and buildings. Efficiency gains are available as well in other transformation sectors, such as coke making.

Industry is the dominant end user of energy, accounting for $46 \%$ of final energy demand in 2007. ${ }^{15}$ To meet massive demands for infrastructure and manufactured goods, China has become the largest, or among the largest, producers in the world of many energy-intensive heavy industrial materials, meaning that even small improvements in average efficiency are consequential. The largest amount of potential energy savings can be found in this sector, especially, although not exclusively, among small and medium-sized enterprises (SMEs).

Tremendous potential also exists in China's commercial and residential buildings. According to national bureau of statistics (NBS, 2009), it is estimated that China builds about 4 billion $\mathrm{m}^{2}$ of new

\footnotetext{
${ }^{15}$ Because of differences in conventions, the IEA's energy figures differ slightly from those from the China's National Bureau of Statistics, which would attribute a higher share of energy demand to the industrial sector.
} 
floor space every year. The building sector represents $25 \%$ of the country's total final energy consumption (IEA statistics, 2010), while the building and industrial sectors are key targets of China's efforts to strengthen energy efficiency. Standards for consumer appliances and office equipment, demand for which is growing quickly in China, have already saved large amounts of energy, and introduction of gradually tighter standards holds promise of further savings.

\section{India}

In India, the energy use for the generation of electricity has increased steadily in the last three decades, growing at an average rate of $2.8 \%$ a year. Energy intensity, the average energy consumption by GDP, however has improved rapidly in India since the mid 1990s, and by an average of $4.3 \%$ yearly since 2000 (BEE, 2010). This rapid improvement is mostly due to the introduction of modern, efficient technologies throughout the end-use sector. Despite this success and the specific effort devoted to improving lighting, recent studies estimate that similar efficiency efforts for refrigerators, window air conditioners, motors and industrial processes could save up to $4.3 \%$ of total electricity consumption (McNeil et al., 2008). Recent studies estimated that the biggest costeffective potentials are in industries and buildings (IEA, 2010). Improving the power generation sector should also be among top priorities. India's coal-fired power plants are among the least efficient in the world and the construction of new thermal power stations would be a cost-effective way of improving efficiency. There have been some positive achievements in energy efficiency in the past few years, such as the enactment of the Energy Conservation Act in 2001 and the creation of the Bureau of Energy Efficiency (BEE) in 2002.

Figure 4: Total final consumption by fuel by sector for India

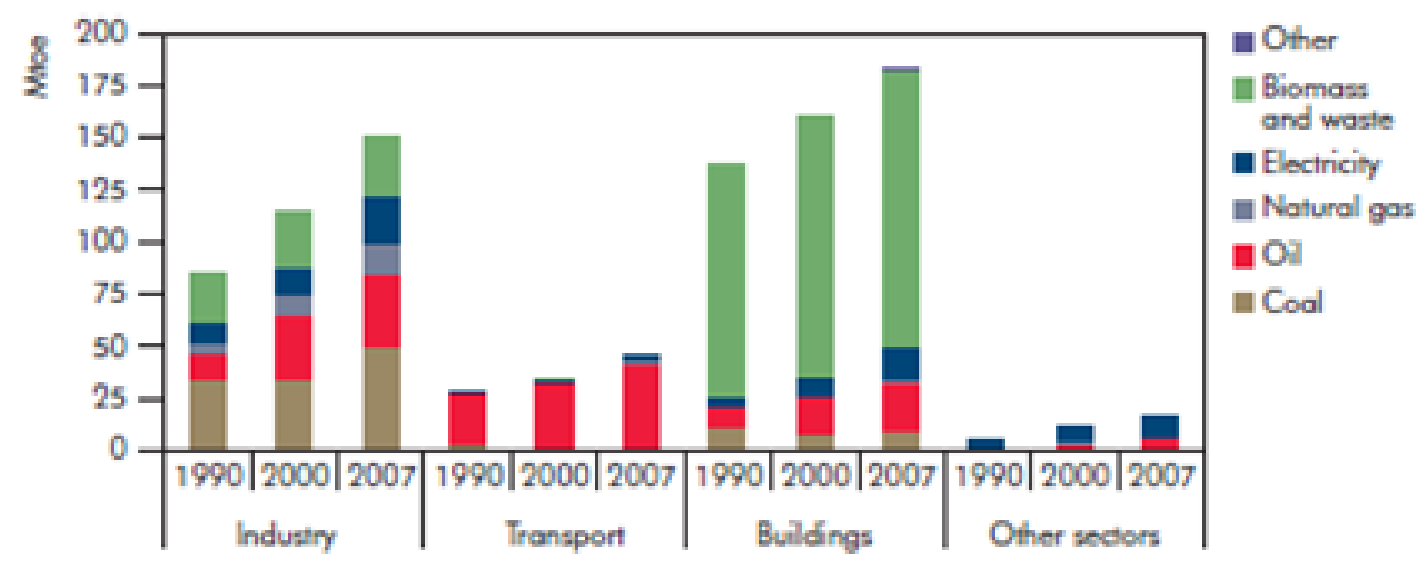

Source: ETP, 2010

The importance of energy efficiency in Indian energy policy has steadily increased in recent years. In addition to the creation of the BEE in 2002, the National Mission for Enhanced Energy Efficiency (2010-2015) introduced several government instruments to facilitate EE development. In December 2009, the Ministry of Power (MoP) announced the creation of fiscal instruments the Partial Risk Guarantee Fund (PRGF) and the Venture Capital Fund for Energy Efficiency (VCFEE). Although it is too early to assess the impact of these instruments, government efforts to address some of the most enduring barriers to EE financing are most commendable. ${ }^{16}$

\footnotetext{
${ }^{16}$ In 2010, the Government of India also signed an MoU with HSBC to work closely on the establishment of the EE financing platform (EEFP). This initiative will help to develop risk mitigation instruments. This work comes in addition to the guidelines and tools developed by BEE on partial risk guarantee and venture capital funds.
} 
Despite recent government efforts to improve energy efficiency, obstacles and untapped potentials remain. Figure 4 shows the steady evolution of final consumption by sector in India.

\section{The challenge of financial structures}

Page | 26 Administrative and legal realities influence the financial structure of a country. They can create, among their many consequences, difficulty in accessing finance or additional risks on foreign investments.

Moreover, among foreign investors, getting money back from China can be a real concern. China's State Administration of Foreign Exchange (SAFE) still strictly controls foreign investors' ability to repatriate foreign exchange (Personal conversation with equity investors, 2009). ${ }^{17}$ This policy, originally created to conserve scarce foreign currency, is still applied and has been identified as a recurring concern by interviewed investors. Dealing with such uncertainty can add months and significant legal costs to project developers in China. ${ }^{18}$

The cap on interest rates is another recurring obstacle to foreign investment in the Chinese clean energy market. In terms of credit rating, the majority of energy project investments in China are graded as "junk bond" investments. ${ }^{19}$ As such, the return to the investor must be up to $20 \%$ a year to cover its risk. Yet, Chinese laws limit interest rates to less than $10 \%$ on foreign shareholder loans. As such the banking lending structure in China does not enable intense credit financing - even less so in 'risky' projects. The 10\% cap on interest rates imposed in China on all foreign investments means that no risk premium can be attributed for risky projects.

Fiscal policies - and particularly the value added tax (VAT) - can be another deterrent to foreign investments in clean energy. In China, the government taxes one-third of any project's revenue over the lifetime of the project through two major taxes among which the VAT tax hits hardest. The VAT tax requires clean energy developers to typically pay $17 \%$ of their revenues to the government. As a matter of comparison, coal producer pay $13 \%$ on that same tax (Chandler and Gwin, 2008). Private investors used to be shielded from the corporate income tax, but this is no longer the case.

Although less salient, hurdles in the legal and banking structures of India also exist. The banking structure in India is very concentrated between Industrial Credit and Investment Corporation of India (ICICI) and the State Bank of India (SBI). Smaller banks (such as YES Bank - a niche bank with among other things very specific programmes for energy efficiency) are finding it difficult to penetrate the market. ${ }^{20}$ Sathaye et al. (2006) have also underlined that the role of development banks in promoting industrial energy efficiency in India has been rather limited.

Potential investors in India face important regulatory hurdles and other constraints that make it difficult to attract foreign direct investments (FDI). In 2006, China had FDI of USD 72.4 billion, while India had USD 6.6 billion. The Indian energy market is still characterised by perverse

\footnotetext{
${ }^{17}$ Such concerns were expressed during the RE Financing forum at the IEA in September 2008 where investors voiced they concerns over past experiences in both China and India, regarding breach of contracts and no return on investment funds.

${ }^{18}$ Other limits to foreign direct investments are: (i) the investor cannot make a direct investment in the project but must create a corporate joint venture into which it can invest;.(ii) the investor cannot easily make a "preferred stock" investment, and thus cannot get a priority return on investment; (iii) the investor cannot lend money to the joint venture; (iv) without also making a major equity investment; and (v) even if the investor makes a major equity investment, a shareholder loan, as previously discussed, is generally not permitted to collect an interest rate equal to the risk involved.

${ }^{19} \mathrm{~A}$ bond rated 'BB' or lower because of its high default risk. Also known as a "high-yield bond" or "speculative bond".

${ }^{20}$ Interviews with Dalkia, Alvoe equity fund and conference at the IEA in September 2008.
} 
incentives mainly due to continued subsidisation of electricity. Failures to implement EE benchmark for imported technologies presents another important obstacle to higher EE implementation. Although the Government of India (GOI) recently increased EE prioritisation, the market is not yet mature. Sathaye et al. (2006) emphasise the relative lack of private sector EE service delivery mechanisms (such as ESCOs) as a specific barrier to energy efficiency in India. Barriers that prevent faster penetration of EE technologies in India are influenced by prices, administrative structures, fiscal policies, etc.

The challenge of accessing capital and liquidity in emerging economies is not limited to foreign investors; such hurdles also apply to national investors.

Overall this section underlines that the realities of emerging economies - prioritisation, legal and banking structures - can add to the difficulties of accessing finance for EE projects. Beyond the small size of end-use EE projects and the many risks associated with them, the economic and regulatory context of emerging economies can prove additional challenges to EE financing. Weak institutional track records, protective regulatory banking systems, and risk-averse lending structures all result in an increased difficulty for the population to get enough liquidity for their basic needs, let alone for investing in EE projects. The consequences of these obstacles are presented in the next section, which considers the EE investment gap.

\section{Energy efficiency investment gap}

\section{Public investments}

Results from both literature review and primary data gathering identified the many difficulties still hindering EE project investment including: the high risks associated with EE projects, the small size of the projects, and enduring uncertainty surrounding EE savings.

Based on primary data gathering as well as semi-structured interviews, Figure 5 illustrates the evolution of $E E$ investments in the last decade for three large financial public institution - the World Bank group (WB), the International American Development Bank (IADB) and the Asian Development Bank (ADB). ${ }^{21}$

Figure 5 underlines that although EE investments are rising, the committed figures are still far from the estimates needed to reach the 450 Scenario. The WEO 2009 estimates the necessary yearly additional investments in EE improvements to be USD 299.4 billion. Although governments are committing increasing amounts to the financing of EE projects, the EE investment gap is still tremendous.

Examples of public investments can also emerge from national institutions such as in China where the China Energy Conservation and Environmental Corporation Group (CECEP or CECIC), a state-owned national agency, has been investing large amounts of money in energy conservation projects. Since the year of its establishment (1988), the group has invested USD 297 million (RMB 23 billion) in national energy conservation capital construction projects, brought more than USD 4.5 billion (RMB 30 billion) local investment, promoted 13 major categories of conservation projects, and accomplished more than 3000 major projects. ${ }^{22}$

\footnotetext{
${ }^{21}$ These three public financial institutions are presented here because data was publicly available for them and they are representative of three regions.

${ }^{22}$ As such, CECIC has been investing directly in projects for the renovation and retrofitting of industries and buildings. They also act as first party financier in cases where managers have difficulties finding capital for a project.
} 


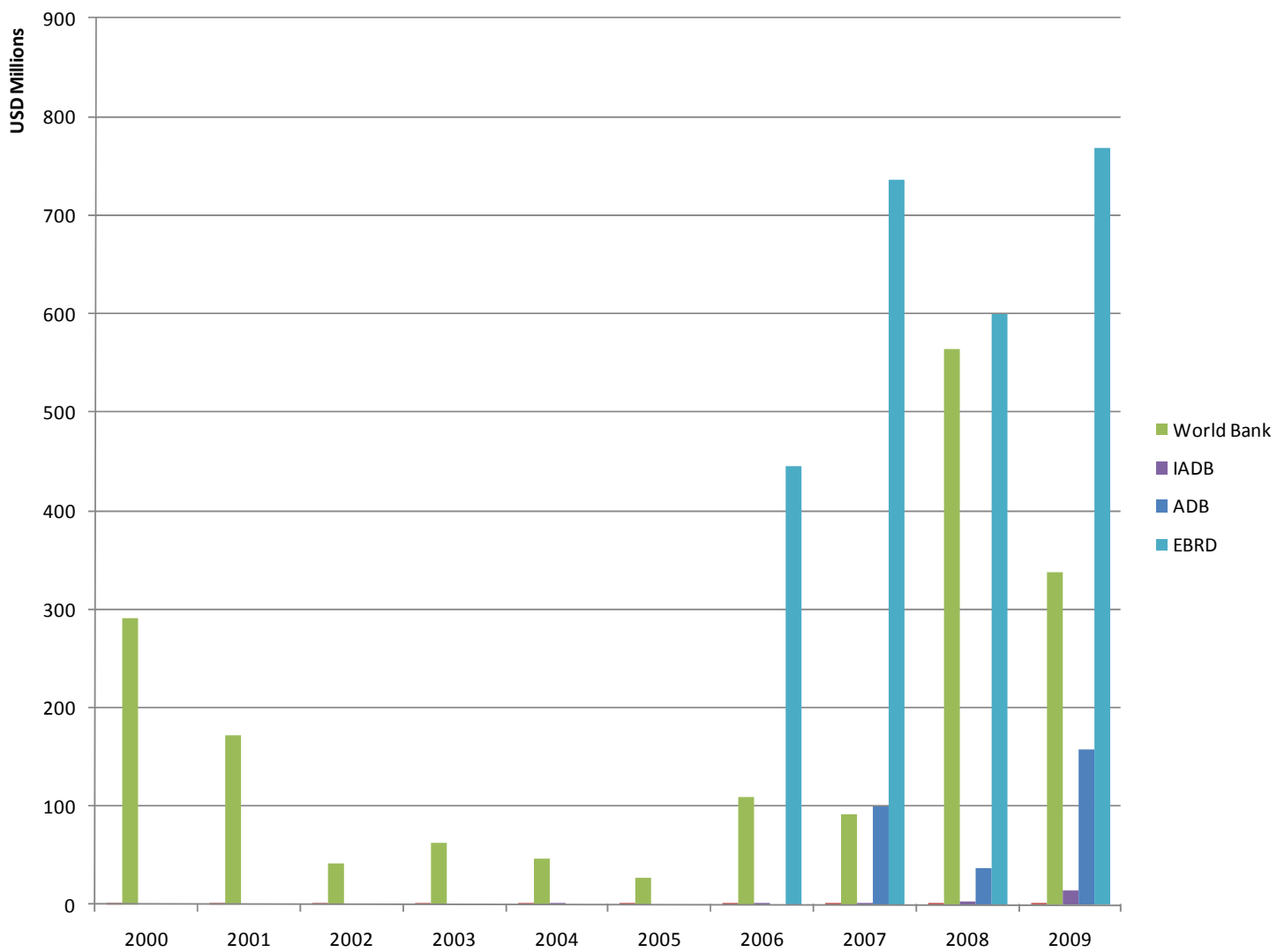

Note: Please note that the data were collected by individual agencies; as such they do not encompass the same elements for each. For instance the EBRD data encompasses leveraged private money in addition of the money invested by the EBRD alone. The World Bank by contrast does not take into account leveraged money of private investors; however it tends to consider renewable and EE investments together.

The shortfall of public investments in energy efficiency is still a matter for concern. Although the public sector cannot be expected to face the challenge alone, the United Nations Framework Convention on Climate Change (UNFCCC) estimates that $86 \%$ of the needed investments should come from the private sector. The current commitment level of public financial institutions still falls short of triggering adequate private-sector financing.

\section{Private investments}

Figures 6 and 7 underline that private investments in energy efficiency - available to public domain - are still limited (i.e. considering the McKinsey estimate of USD 170 billion of available cost-effective investments yearly; McKinsey, 2008). No database collects private financial institutions' investments in energy efficiency; the data was collected by an independent consultancy agency, New Energy Finance (NEF), which tracks investments in clean energy. It records all private equity (PE) and venture capital (VC) transactions in both $\mathrm{EE}$ and renewable (RE) sectors worldwide. NEF has local agencies in both India and China and was able to gather 
additional information from local stakeholders when they were mandated for the task. ${ }^{23}$ The trends in EE investments presented here cover worldwide investments in PE/VC for industries and appliances. No data on existing building transactions was found, beyond the presence of 25 projects in India "green build" and two demonstration projects in China.

Figure 6: New investment worldwide by financing type efficiency and power storage

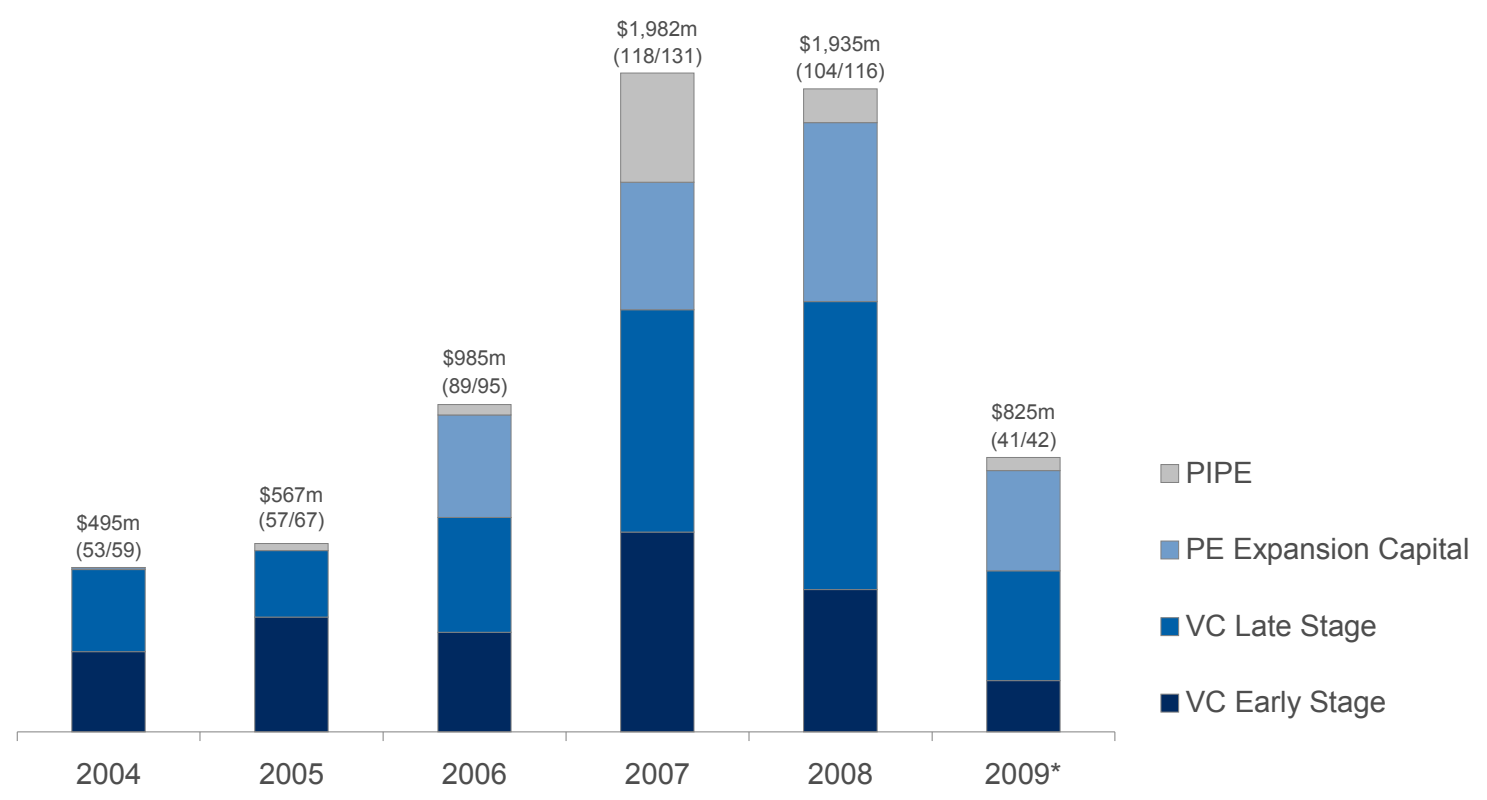

Source: New Energy Finance, 2009; * 3 first quarters; \$ = USD

The overall figure of USD 825 million only accounts for $0.5 \%$ of estimated cost-effective potential of USD 170 billion.

These two figures on the evolution in investments for PE/VC in energy efficiency and power storage reveal that, although still insufficient, EE investments are increasing, most significantly in the transport and industrial sectors - respectively $172 \%$ and $76 \%$. The building sector rises by $36 \%$ with the biggest share coming from the VC sector. This is not surprising since personal independent apartment deals are too limited for private equity investors. Such class of investors would probably invest in commercial sector buildings, however such deals still remain quite limited. ${ }^{24}$

Although the results should be considered with caution since they are limited to a certain asset class (PE/VC), and mostly consider investments made in companies to manufacture technologies rather than companies implementing them, the results confirm a missed market opportunity. They underline the difficulty in getting access to investments trends for EE projects. Many lessons can be learned by the quantitative and qualitative results of the surveys.

\footnotetext{
${ }^{23}$ NEF has been in place since 2005. It has local agents based in both India and China to monitor the evolution of private-sector investments in different areas. The data were collected through their database, as well as through a series of interviews with some fund managers, commercial bankers and project developers.

${ }^{24}$ In addition, the NEF data focuses on investments in companies which create new technologies rather in companies implementing the technologies.
} 
Figure 7: New VC/PE investment worldwide by sector efficiency and power storage

Page | 30

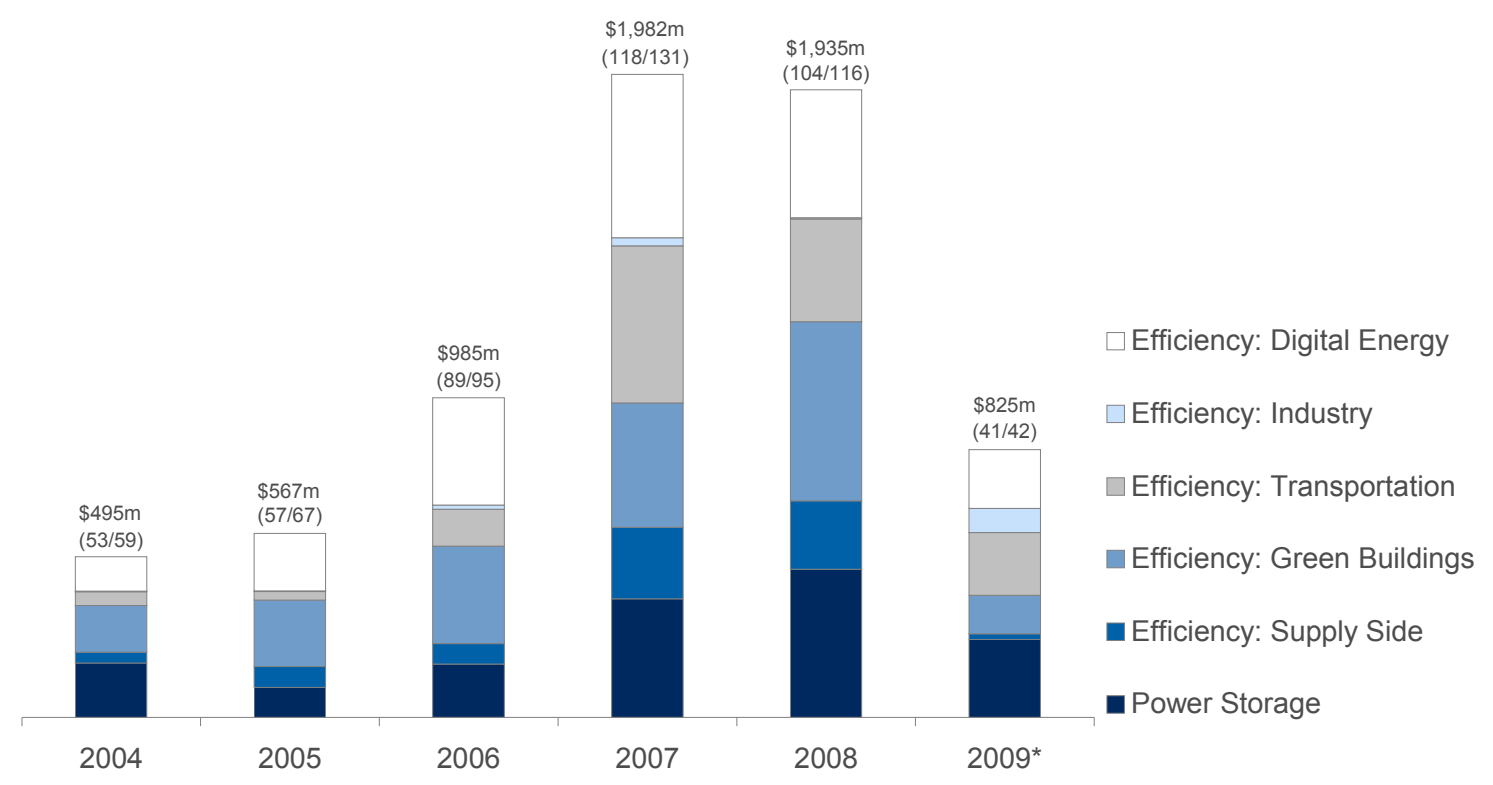

Source: New Energy Finance, 2009

*2009 extend to Q2 only; \$ = USD

\section{Lessons from the findings}

\section{More systematic data collection needed}

The meagre quantitative results coming out of the survey and interviews underline the need for systematic data gathering. Although public financial institutions can be tracked down, the portfolio of private investments is much more difficult to identify. Private financial institutions were very eager to participate in the questionnaire, and were overall quite keen on meeting with the IEA and sharing their experience in EE financing, yet very few revealed the extent of their quantitative involvement in EE projects.

Two main factors help explain this phenomenon. First, it is difficult to define - identify - what EE investments comprise. If a bank decides to invest in a Light Emitting Diode (LED) manufacturer, it is quite straightforward to consider the entire investment as an EE investment. On the other hand, should a bank decide to invest in road construction using some EE technologies, it becomes less evident to determine the portion of investment incumbent to $\mathrm{EE}$. Second, as for any other investments decisions, information can be pivotal in determining the success/failure of an investment deal. As such banks are reluctant to share this information with the public arena and potential competitors.

In addition, there is no one entity responsible today for collecting level of investments in EE financing. Although New Energy Finance (NEF) tracks down VC and PE in clean technology and EE investments, it has no access to overall EE portfolio investments which are outside the public domain. Moreover, although the Carbon Disclosure Project (CDP) follows the level of emissions associated with financial institutions' projects, again there is no individual breakdown of investment level by project, even less so of EE projection of investment. 
Yet such collection of information is crucial to identify trends in investment and the action gaps and the future areas for investments. Moreover, systematic data collections on EE investments as well as the heightened broadcasting of successful case studies were underlined as crucial areas to facilitate private sector involvement. Such data collection would enable the identification of leverage point for action. Increased dialogue between the policy makers and private financial stakeholders could contribute to the sharing of information and help unlock EE investments. Improving the collection of data and communication channels is key to promoting EE investment potential. It would seem that the implementation of a body responsible for collecting this information, as a clearing house, to pass it on to the general public in an aggregated way, would be very useful. This point will be further underlines further on, suggesting the creation of an EE finance action network (EEFAN).

\section{Communication channels and certification protocol are required}

This increased dialogue and information sharing is also crucial in reducing the uncertainties surrounding energy savings. Again, interviews underlined the high risk that investors still associate with EE projects. Investors need more - or clearer - information regarding EE technologies. Such information will enable them to translate uncertain energy savings into certain revenue streams of investments. Respondents from the survey underlined the riskiness and lack of trust in EE technologies as key barriers in explaining the large gap between economic potential and project realisation for energy efficiency. As one investor argued, "the reasons why the energy efficiency market has not caught the imagination of the financial institutions are because they are still perceived as too risky." An effective means of tempering this high risk perception is an increased diffusion of laymen information on EE project advantages. Many respondents to the survey underlined the importance of ensuring the implementation of appropriate market conditions over and above that of increasing the actual level of money. One independent consultant who has been working in India on EE projects for over 30 years was adamant that "people are looking at EE financing as the Holy Grail; but I don't think that it is the right approach, because they are actually issues at different levels and financing is not necessarily the most important." In that same conversation, the respondent went on to argue that he "seriously believed that the barrier was not actually financial. Instead, government should focus on non-market barriers (i.e. organisation, market and risks)." Establishing proper channels of verification and enforcement are essential in building investor trust and attraction to EE markets (the difficulties of establishing such certification protocols were explained earlier, in Box 1).

Evidence from interviews suggests that the financial community involved in EE financing would welcome increased information, training and experience sharing. One could imagine the creation of an international platform for better co-operation and communication between the public and private financial sector. Such a platform would aim to establish a common language and better understanding between the different sectors. In addition, most local and national banks interviewed during missions to both India and China underlined the need for increased expertise and experts in EE auditing and financing specificities. Many of interviewed stakeholders suggested that training and outreach in energy efficiency for the financial sector is needed and would be welcome. 


\section{The need for developing internal champions}

Interviews revealed that the presence of an internal champion with both knowledge and an intimate conviction of energy efficiency's worth, makes a marked difference in the bank's decision to take on EE projects. As underlined by an IFC employee in China, "EE project managers generally have very little knowledge on how to package the project to make it banker friendly." As such, the presence of a counterparty and advocate of EE within the bank can make a significant difference. Despite an existing strong interest, bankers interviewed expressed a sense of lost opportunity as they did not know where and how to concentrate their efforts towards EE financing. Having at least one internal proponent within an institution can help overcome this barrier.

Section 1 overviewed the theoretical and real-life challenges of EE financing in emerging economies. Evidence from the survey shows investors' eagerness to seize EE market opportunity, pending the creation of enabling market conditions including increased data gathering, better channels of communication between the public and private sectors, and the training of champions within banks. Building on these findings, section 2 gauges the success of current international and national mechanisms in leveraging private investments: What explains their successes and failures? What lessons can be learned for risk mitigation and triggering of private investments? 


\section{SECTION 2: Existing national and international mechanisms}

Section 1 identified the many types of risks affecting investor and lender willingness to finance energy efficiency. This section questions whether current mechanisms are sufficient to mitigate these risks, including the additional categories of risk found in emerging economies. More specifically, this section presents four examples of financing enhancement tools and their success: contingency financing through the implementation of a loan guarantee programme in China; an awareness and training campaign in India; a public/private partnership (PPP) through the development of a revolving fund in Thailand, and finally the Clean Development Mechanism (CDM) and its role in leveraging private investments in energy efficiency in reducing risks associated with Energy Efficiency. Again, results from local interviews and survey feed in the analysis.

The figure below is a graphic illustration of the factors identified as contributing to a high risk perception by stakeholders in the EE market. This figure however is not comprehensive and does not cover other barriers identified earlier in Figure 1 (such as technical, information failure and other).

Figure 8: Factors contributing to high risk perception and tools to help address the issue

Factors contributing to high risk perception

Factors mitigating high risk perception

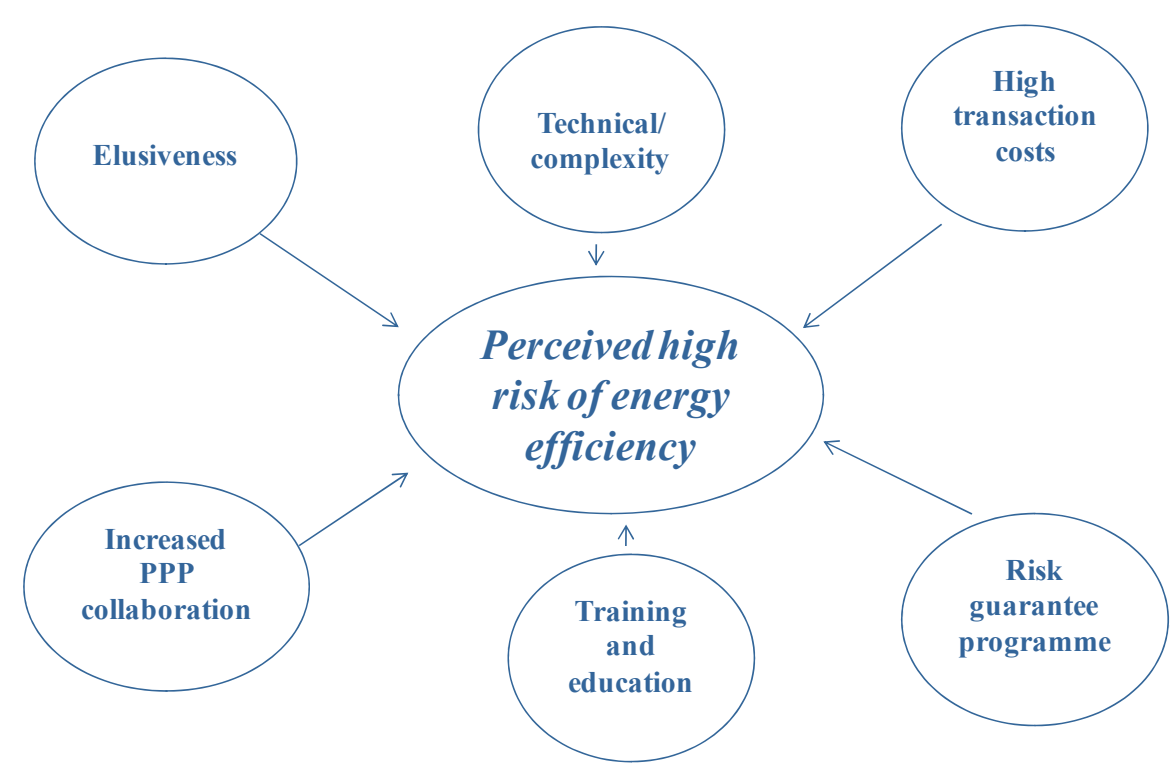




\section{Case study 1 - Contingency financing: the IFC CHUEE programme in China}

\section{Page | 34 Process}

Since December 2007, the International Finance Corporation (IFC), with the help of the Global Environmental Facility (GEF), has implemented risk-guarantee programmes in China. This mechanism runs by the name of China Utility-based Energy Efficiency Finance Programme (CHUEE). It involves a USD 15 million fund from the GEF for the first round of projects, which enables the IFC to provide guarantees to three main Chinese banks: the Industrial Bank (IB), the Shanghai Pudong Development Bank (SPDB), and the Bank of Beijing (BoB). Figure 9 details the process for the mechanism.

Figure 9: The organisation of an IFC/GEF guarantee programme
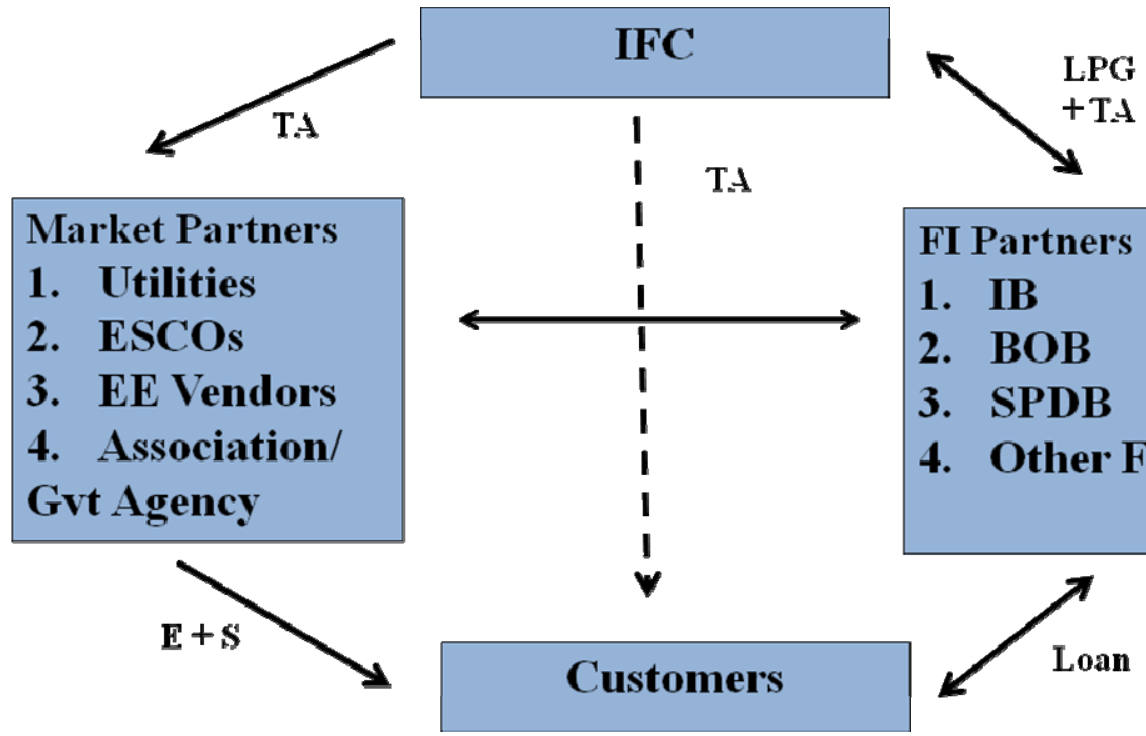

\section{FI Partners}

1. IB

2. BOB

3. SPDB

4. Other FIs

TA: Technical Assistance

CA: Cooperation Agreement

LGP: Loan Guarantee Programme

$\mathrm{E}+\mathrm{S}$ : Equipment, Engineering Service

Source: Presentation by Cufeng Dai (IFC) at Green Credit Policy Workshop, June 2009

As illustrated, contingency financing in the form of loan guarantee programme (LPG) such as the CHUEE provide loan guarantees and technical help to financial institutions (FI). During the initial transaction, the IFC guarantees $75 \%$ of the loss on the first $10 \%$ loss, while the local bank remains responsible for the remaining $25 \%$. As such, CHUEE offers elements of risk mitigation for the investors on two levels: counterparty risk level and risk perception. Box 2 illustrates in more detail the amounts of money spent on the two first rounds of IFC projects developed in China. 


\section{Box 2: Risk sharing guarantees in China with Industrial Bank}

- On 25 February 2008, the IFC and Industrial Bank signed a co-operation agreement to increase their collaboration.

- This began the second phase of the IFC China Utility-based EE finance programme (CHUEE).

- Through this agreement, the IFC provides USD 104 million in risk-sharing facility to the Industrial Bank.

- This risk sharing facility will in turn allow the Industrial Bank to provide USD 210 million in EE loans.

- It is expected that this partnership will help reduce $5 \mathrm{Mt}$ of $\mathrm{CO}_{2}$ emissions yearly (which is equivalent to replacing ten 100 -megawatt coal-fired power plants in China).

- The first phase of the project had seen the IFC providing a risk-sharing facility of USD 25 million, with which the bank had provided over 46 energy efficiency and greenhouse gas emissions reduction projects for a total of USD 126 million.

- Implementation of these projects (wasted heat recovery, boiler retrofitting, power saving, cogeneration for district heating) is expected to reduce $\mathrm{CO}_{2}$ by more than $3.5 \mathrm{Mt}$.

- The establishment of trust and the increased signal of feasibility to the private sector were keys to the success of this mechanism. Despite being focused on larger industrial projects, the IFC intends to diversify through CHUEE III. This next stage intends to scale up the level of financing through a partnering with the China Clean Development Mechanism Fund (CDMF). It also intends to extend the scope of the target by providing advisory services to financial institutes and service providers for industries.

Source: IFC press release (2009)

\section{Achievements}

Though initiated in China only in late 2007, the CHUEE scheme has been implemented in other regions (for example in Eastern Europe) for ten years, with great success. As of March 2009, around 100 loans have been approved by the IFC for a total loan amount of USD 471 million. The annual greenhouse gas emissions reduction is 12.04 MT. SMEs represent the highest percentage of borrowers (35\%). Table 2 below summarises the projects financed by the IFC: it shows a high proportion of power generation and large industrial processes. To date, less than two risk-guarantee projects have defaulted. ${ }^{25}$ Such observation reinforces the notion that counterparty and operational risks are not as significant as described by investors in interviews. Stronger broadcasting of successes would be welcomed and could help to readjust the risk perception.

Table 2: Examples of IFC loan guarantees projects in since 2007

\begin{tabular}{|l|r|r|r|r|}
\hline \multicolumn{1}{|c|}{ Project } & $\begin{array}{c}\text { Loans } \\
\text { (mln RMB) }\end{array}$ & $\begin{array}{c}\text { Total investement } \\
\text { (mln RMB) }\end{array}$ & $\begin{array}{c}\text { Term } \\
\text { (year) }\end{array}$ & $\begin{array}{c}\text { CO }_{2} \text { reduction } \\
\text { (ton/year) }\end{array}$ \\
\hline Power Plant EE project & 12 & 18 & 5 & 1200 \\
Iron \& Steel TRT Project & 13 & 39.80 & 3 & 3300 \\
Cleaning Service & 10 & 19.59 & 3 & 7000 \\
Hot Condensed Water & 1 & $\mathrm{~N} / \mathrm{A}$ & 1 & 10000 \\
Agri High Tech Biogas & 16 & 49.77 & 5 & 83000 \\
Landfill Biogas & 8 & 9.50 & 5 & 13300 \\
\hline
\end{tabular}

Source: Presentation by Cufeng Dai, Operations Officer, June 2009, Beijing

\footnotetext{
${ }^{25} \mathrm{Cf}$. private conversation with Alan Miller from the IFC.
} 


\section{Lessons}

Primary information collection through interviews and discussion with key participants reveal that contingency financing has been very successful in raising the interest and involvement of private financial stakeholders in China. Personal conversations with IFC analysts emphasise that in the second round of investments, private banks were turning to the IFC to get involved. The implementation of loan-guarantee programmes has, in this case, allowed the IFC to trigger a sustainable circle of investments by reassuring investors and raising their interest. The IFC even had to turn some banks down.

\section{Indirect benefits: capacity building of financial institutions}

The success of this programme can be explained by many factors including a key indirect benefit: the increased training and capacity building within banks and the development of internal champions. Conversations with stakeholders revealed the importance of internal champions seeing through reform projects. As the risk guarantor, the IFC role extended beyond that of financial backup; it was also able to provide training and guidance to the local banks in EE specificities. As underlined by IFC partakers to the process, on average all the local bank personnel who participated in the transactions have been promoted at least once or twice since the start of the mechanism (December 2008, personal conversation with IFC staff). Although specific training and one-on-one guidance was necessary for the initial transactions, the deals that followed were orchestrated by the local banks. The programme would probably not have been so successful without the indirect training of personnel and bankers. Such sustainable success was also found in the Eastern European implementation of the programme by the IFC.

While the guarantee of the loan was helpful in getting the private sector's initial involvement, the indirect training and capacity building rendered the initiative sustainable. The eagerness of non-participating local banks to participate in the next round of investments stands as a testimony that once trained and reassured about the expected energy savings of energy efficiency measures, private financiers are keen to partake in energy efficiency investments.

\section{Government buy-in was key in the success of CHUEE}

The successful track record of CHUEE owes a lot to the conditions in which the IFC operated. CHUEE would never have succeeded without the Chinese government's prioritisation of energy efficiency. Government buy-in was another key element in the success of the mechanism. The risk-credit guarantee programmes have enabled a sustainable market transformation. While the first transactions in China were all accompanied by the IFC, the second set were conducted more independently by the local banks, both in terms of human resources and in the level of risk guarantee provided by the IFC. The second transaction only saw IFC guarantee $60 \%$ of the transaction instead of $75 \%$. As pointed out by a Hong Kong investor, it is usually very difficult for foreign investors to get significant stakes in Chinese companies. The fact that IFC was allowed to cover over $75 \%$ of the risk in their deal structure with national banks was very exceptional. In this case, it was government exception that allowed the deal to happen.

Hence, by providing first loss guarantee programme, with no direct cash injection, the IFC managed to reassure investors, indirectly training them by accompanying the first market transactions, at no direct costs. Section one underlined that the Chinese policy context can 
sometimes hinder foreign investments. Preliminary discussions by the IFC with the government overcame this obstacle. The IFC was so successful in designing and implementing its programme that within six months of gaining Chinese government approval to provide guarantees with foreign currency, the IFC developed an EE pipeline of projects worth more than USD 650 million.

The scheme is very encouraging. ${ }^{26}$ The very few instances of project default reinforce the importance of broadcasting success stories to ensure adequate risk evaluation of EE projects. After two rounds of the CHUEEE, the IFC had triggered demand from commercial banks that were asking to be part of the programme. Building on their success in China, the IFC has started to develop the same structure in India. However, these activities are still at preliminary stages and should be evaluated by a later study. The Indian market is not yet as mature as the Chinese market. The same is true of a number of EE institutions. India is however catching up at great speed, as illustrated in the next case study which analyses the impact of indirect training and capacity building on the Indian banking sector.

\section{Case study $\mathbf{2}$ - Training and capacity programmes: cluster financing in India}

\section{Process}

In the 1980s, the Indian government realised that tools developed to finance large-scale industries were not reaching small-and medium-sized enterprises (SMEs). To unlock this potential, the government designed a programme of cluster financing to increase the financing capacity of SMEs without specifically targeting energy efficiency. The mechanism helps aggregate similar types of financing requests and presents them to the banker as a single bundled project. Figure 10 illustrates the mechanism.

Two specific programmes were relevant to the development of cluster financing:

- The State Bank of India (SBI) set up a technology upgrade programme (Programme Uptech) for all SMEs from every sector in 1988.

- The Small Industries Development Bank of India (SIDBI) was then established in 1990. Within a few years, SIDBI has become the most important financial institution in the development of SMEs in India.

Both programmes targeted the transaction costs associated with the loans, which was often detrimental for SMEs, by bundling similar projects. The approach was technology focused.

More recently, the BEE has developed training and capacity programme specifically targeting energy efficiency in SMEs. Initially this programme enabled the diagnosis of 25 SME clusters in the country and developed specific manuals/booklets which help to train energy auditors on the specificities of EE financing.

\footnotetext{
${ }^{26}$ The World Bank also put in place a loan guarantee programme in collaboration with GEF. Contrary to the IFC loan guarantee programme, this scheme concentrated on ESCOs and ESCO development. The guarantee fund of USD 22 million was granted by GEF and is held by the Ministry of Finance (MOF). The China National Investment Guarantee $(I \& G)$ is in charge of the execution of the project.
} 
Figure 10: Cluster lending approach adopted in India

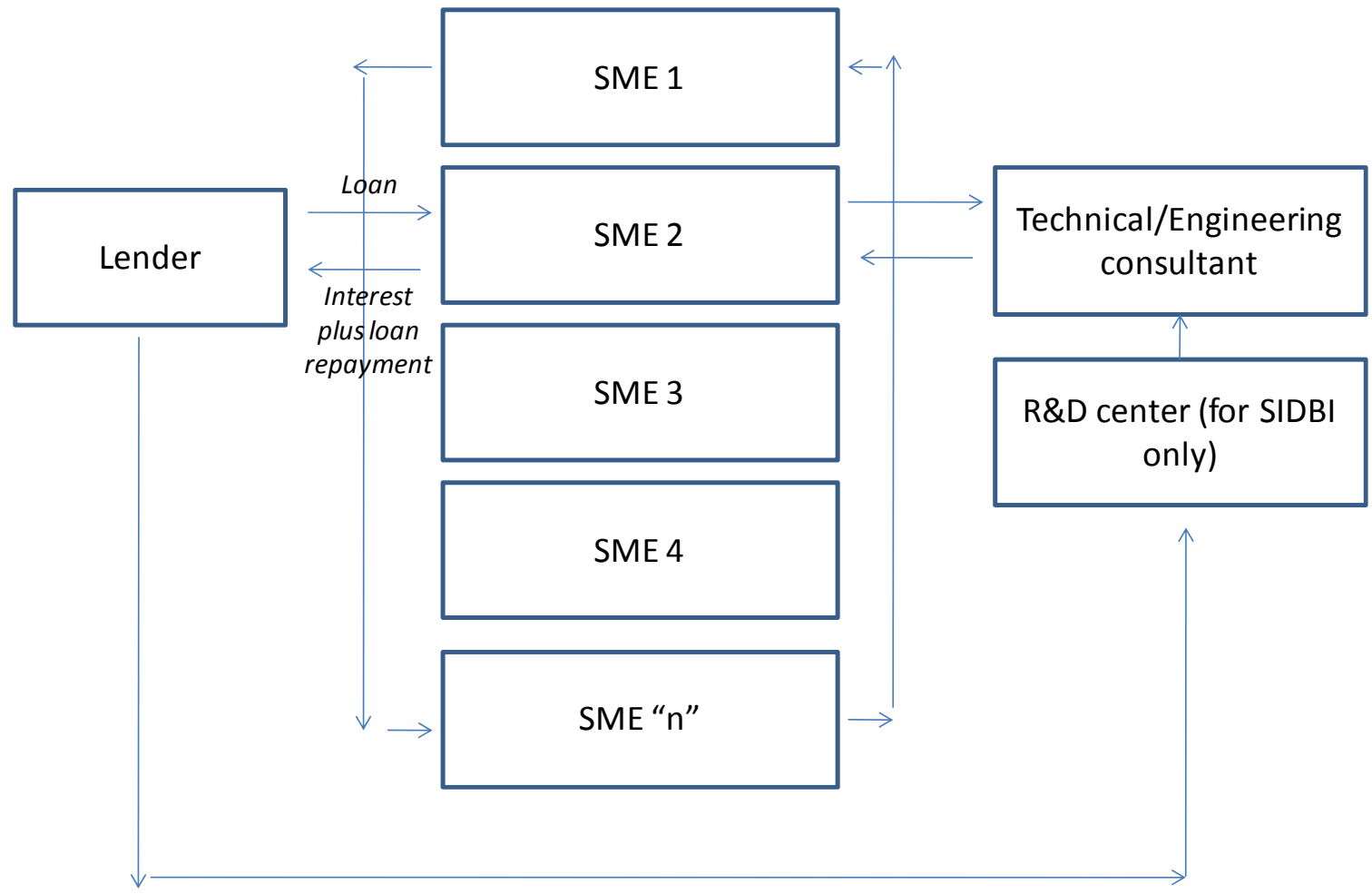

Source: Taylor et al., 2008

India has nearly 13 million micro, small, and medium enterprises which constitute more than $80 \%$ of the total number of industrial enterprises in the country. Small industries have a $45 \%$ share of the total manufacturing output and contribute to nearly $40 \%$ of the total exports in the country. A BEE survey in 2008-09 estimated that the 35 cluster units used 6 mtoe in end-use energy consumption, with a savings' potential of around $20-25 \%$ in energy intensive areas (BEE, 2010).

Building on these findings the BEE has initiated a programme specifically targeting SMEs and their energy saving potential. The BEE provides energy use and technology audit, as well as the capacity building of stakeholders to help the implementation of EE measures. An aside of this programme is the training of bankers through workshops explaining the advantages of EE programmes. In addition to this programme, the BEE, in collaboration with Alliance to Save Energy and the IFC, has developed guidelines to facilitate municipal EE projects.

Although it is too early to gauge the impact of this programme, it augurs well in the training and awareness raising of national bankers, and is a great step towards mitigating the risk perception.

\section{Achievements}

Both SBI and SIDBI supported technology development work in SMEs. SBI contracted external industry experts and, where necessary, research, development and demonstration (RD\&D) organisations, while SIDBI created a specialized agency, the India SME Technology Services 
Limited. By aggregating similar requests, the scheme reduced associated transaction costs for investors while building the profile size of the projects.

Training programmes and seminars were conducted, as well as SME-level studies which covered more than $20 \%$ of SMEs registered within the cluster. The focus was on appropriate technologies for process improvement, energy efficiency, pollution abatement, low-cost automation, introduction of management information systems, and above all, creation of an improved working environment.

The two banks also initiated the establishment of public/private partnerships. SBI Project Uptech co-ordinated with various government agencies including the Centre for Development of Glass Industry and the Central Glass and Ceramic Research Institute. In a similar vein, SIDBI appointed the National Productivity Council to work on reducing heat losses from locally fabricated furnaces in more than 1000 aluminium, brass, and steel utensil manufacturing units in Jagadhari (Haryana). The cluster previously utilised wood and fuel in poorly designed and inefficient furnaces that had been fabricated by national companies. Moreover, this approach allowed preparing the field for more specific and targeted BEE programmes such as the SME EE programme in 2002.

\section{Lessons}

\section{Training and capacity building created long-term incentives for actors}

Although not directly targeting risk mitigation or EE financing, the Indian development of cluster financing again highlights the impact of training and capacity building in reducing risk perception and triggering private-sector interest. By favouring increased communication between the SMEs, as well as sharing of experiences in terms of EE possibilities, the participation of a federal government bank allowed the local training of SMEs and smaller banks. In the interviews, many financial institutions - especially national and local institutions in both India and China - expressed a willingness to receive more information and even training in the main aspects of energy efficiency.

Recognising the importance of information collection and dissemination, the banks initiated credible energy audits and a panel of selected energy auditors and ESCOs to ensure a high level of quality and reliability in technical assessment. For instance, SBI conducted a detailed review of the background and experience of energy auditors, ESCOs and other energy consultants on the panels of the Bureau of Energy Efficiency (BEE), the Petroleum Conservation and Research Association, and others to identify a panel of their own. The Indian EE market has a long way to go in educating and informing all stakeholders in energy efficiency. Personal communication with the BEE revealed the seriousness of the Indian government to address this gap. The bureau has launched an ambitious project of data gathering in EE consumption of buildings. ${ }^{27}$

It is too soon to measure the impacts that the BEE training programme is likely to have on the Indian EE sector, however, it is a notable step in the right direction and should be underlined as such.

\footnotetext{
${ }^{27}$ More recently, the government launched a new agency promoting EE financing programmes: the Energy Service Company, demonstrating its strong commitment to energy efficiency.
} 


\section{Indirect consequence: The emergence of other activities}

The benefits of the clustering approach are evident, prompted further activities and allowed to prepare the field/audience for new projects such as the intiation of the BEE scheme in 2002. In (i) devising additional EE lending schemes; (ii) making efforts to market the new and existing schemes; (iii) empanelling certified, reputable energy auditors; (iv) developing standardised energy audit templates; and (v) developing in-house skills, and/or identifying a pool of external experts to assist on technical matters in the appraisal process.

As underlined in section 1, each sector of the economy faces different EE financing challenges. SMEs are particularly sensitive to transaction costs. Their small size and proportionate equity levels mean that they face challenges similar to those encountered by customers investing in individual end-use projects.

\section{Case study 3 - Public/private partnerships: the Thailand revolving fund and the development of private investments}

\section{Process}

Thailand's Energy Efficiency Revolving Fund (RF) commenced operation in January 2003. In 1992, the Thailand government passed the energy conservation promotion act. In conjunction with this legislation, the energy conservation fund (ENCON) was created. The fund was established to stimulate financial sector involvement in EE projects and to simplify project evaluation and financing procedures.

The fund provided capital at no cost to Thai banks for EE projects. In turn the commercial banks within the process provided low-interest loans to project proponents. The banks are not allowed to charge more than $4 \%$ of interest rates with the loans.

As such, banks are attracted to the loans through the margin that they can make between the $0 \%$ interest rate and the $4 \%$ that they charge. This provides them with a safety net in case of default, and a profit in case of success.

As far as the government is concerned, this scheme bears no cost: the money provided for the loans come from the gasoline tax, implemented in Thailand in the mid-1990s. The rest of the costs in administering a loan application and monitoring is borne by the commercial banks. The first phase of the project consisted of USD 50 million. The maximum loan available from the Energy Efficiency Revolving Fund is THB 50 million (USD 1.25 million) per project. This figure was set to target the fund at medium-sized EE projects, such as replacement of air conditioning chillers in a commercial facility or the installation of EE equipment at an industrial site.

According to a person in charge of implementing the programme for its first two phases, the two major difficulties that they faced was getting the interest of the private sector and aligning regulations to enable these loans. The government overcame the first obstacle by organising a series of seminars to familiarise and train bankers on EE projects as well as renewables. However in the words of a former minister in Thailand: "It is not about the training of the banks...it's just about whether you are able to find a champion" (Personal conversations with the author, March 2010). 


\section{Achievements}

In its first two phases of implementation (up to 2005), the fund was able to save over USD 73.8 million year in equivalent energy savings. The total project costs for that period were close to USD 180.5 million, with only USD 94.7 million coming from the fund loans, which were all paid back and contributed to the next phases of the project. The table below illustrates those savings.

Table 3: Overall energy savings from the revolving fund phase 1 and phase 2

\begin{tabular}{|l|r|r|r|}
\hline & $\begin{array}{c}\text { Phase 1 } \\
\text { (USD mln/year) }\end{array}$ & $\begin{array}{c}\text { Phase 2 } \\
\text { (USD mln/year) }\end{array}$ & $\begin{array}{c}\text { TOTAL } \\
\text { (USD mln/year) }\end{array}$ \\
\hline Project Cost & 85.70 & 94.80 & 180.50 \\
RF Loan & 47.70 & 47.00 & 94.70 \\
Payback Period & 2.40 & 2.45 & 2.40 \\
Electricity & 15.60 & 15.70 & 31.30 \\
Saving & 19.50 & 23.00 & 42.50 \\
Oil Saving & 35.10 & 38.70 & 73.80 \\
\hline
\end{tabular}

Source: Chaiyawat, 2009

The projects funded through the RF were mostly in the industrial and commercial buildings areas (e.g. hospitals, schools, government offices). The table below shows the projects implemented in the first phase of the RF.

Table 4: Energy Efficiency measures implemented in the first phase of the project

\begin{tabular}{|l|r|r|r|}
\hline \multicolumn{1}{|c|}{ MEASURES } & $\begin{array}{r}\text { Investments } \\
\text { (USD mln) }\end{array}$ & $\begin{array}{c}\text { Total savings per annum } \\
\text { USD mln) }\end{array}$ & $\begin{array}{c}\text { Average } \\
\text { Payback } \\
\text { (years) }\end{array}$ \\
\hline Energy Management and control & 2.04 & 0.75 & 2.71 \\
Insulation & 0.21 & 0.24 & 0.88 \\
Process improvement & 5.23 & 2.06 & 2.53 \\
High efficiency equipment & 12.40 & 12.13 & 1.02 \\
Renewable energy & 23.25 & 13.13 & 1.77 \\
Improvement of machinery & 1.10 & 0.61 & 1.79 \\
Air conditioning & 2.85 & 1.03 & 2.78 \\
Electrical system & 0.13 & 0.03 & 4.01 \\
Lighting & 0.07 & 0.03 & 2.53 \\
Cogeneration & 32.7 & 8.20 & 3.98 \\
Boiler & 1.20 & 0.96 & 1.25 \\
TOTAL & 81.18 & 39.17 & 2.07 \\
\hline Source: Apec, 2005 & & & \\
\hline
\end{tabular}

Today, seven years after the first phase of the fund, the scheme is still running. Having started with less than three banks, the fund is now working with 11 banks, and more are asking to join. 


\section{Lessons}

The RF was a great success. It saved large amounts of energy through a cost-effective policy. Moreover, the policy was developed to be sustainable. Although the first two phases of the programme saw government provide $0 \%$ interest loans, the programme then evolved and proposed $0.5 \%$ or $1 \%$ interest loans without losing the interest from the banks - quite to the contrary since the programme kept adding on new partnerships.

This sustainability results from the government's ability to convey the win-win situation in energy efficiency for the banks. In the words of a Thai banker involved in the scheme, the programme allowed the government to increase its competitiveness and reduce its fossil fuel consumption, at the same time as it enabled bankers to enhance customers' credit worthiness, and provide a new range of profitable loans.

In meeting with such success, the development of internal champions within the banks, as well as the initial support of a group of bankers was essential. The domino effect and word of mouth then got other banks on board.

Overall the RF reinforced the importance of developing internal champions, as well as getting the training and capacity building right to ensure the sustainability and contagious effect of a programme in the private sector. Although the government did not provide direct risk guarantee, the margin of difference in the interest rate, as well as the organisation of training and awareness building seminars, enabled the development of trust and knowledge within the private sector, which in turn reduced the risk that they associated with EE projects.

The financing model is simple and straightforward and does not rely on any factors unique to the situation in Thailand. Therefore, it could easily be applied in other economies. Applying the model in other economies would require:

- a revolving pool of funds from which to provide loans - funds for the initial pool could be directly allocated from government revenue or raised from a dedicated tax;

- agreement from the finance sector (banks and maybe other financial institutions) to participate in the financing model;

- commitment of a small number of staff from a government agency to establish the financing model and to carry out a small proportion of the work involved in assessing loan applications, administering loans and promoting the financing model.

Beyond these risk mitigating instruments, it is worth considering the only UNFCCC recognised tool for linking the private sector to clean energy financing. Considering the urgency of implementing EE technologies, as well as the projected weight of energy efficiency for a sustainable energy future, the next case study questions whether any of these findings are applied in current international mechanisms. The study focuses on the only UNFCCC recognised linked between the private sector and clean technology in emerging economies: the Clean Development Mechanism (CDM). 


\section{Case study 4 - International mechanisms: are they contributing to risk mitigation? The case of CDM and its lessons for EE financing}

\section{Process}

The UNFCCC recognises the need for financial resources to help developing countries face the challenge of emission mitigation. The Kyoto Protocol in 1998 confirmed the financial obligations of developed countries in that regard. It is established that developed country Parties of the Kyoto Protocol, as well as Annex II Parties under the Convention shall: "Provide new and additional financial resources to meet the agreed full costs incurred by developing country Parties in advancing the implementation of existing commitments."

This process led to the creation of the only officially recognised link between the private and public sector for clean energy investments in non-Annex I countries: the Clean Development Mechanism (CDM) (Article 12 of the Kyoto Protocol). The CDM serves a dual purpose: (i) emission mitigation and (ii) sustainable development: "The purpose of the Clean Development Mechanism shall be to assist Parties not included in Annex I in achieving sustainable development and in contributing to the ultimate objective of the Convention, and to assist Parties included in Annex $I$ in achieving compliance with their quantified emission limitation and reduction commitment under Article 3."

Once validated, CDM projects are awarded Certified Emissions Reductions (CERs). These can be traded on the European Union-Emissions Trading Scheme (EU-ETS) and as such have a monetary value. The process to generate CERs is long (approximately 12 months) and tedious. Projects need to go through the approval process of the UNFCCC Executive Board (EB). According to Article 12 paragraph 5.c., projects need to prove their additionality - both financial and environmental - to be approved. ${ }^{28}$ As the CDM process evolves, a number of exante methodologies have been developed and can serve to accept new technologies; these are referred to as deemed savings methodologies. These methodologies are used to calculate, measure and estimate the potential emission reductions of various projects and are often specific to a given technology. ${ }^{29}$

\section{Achievements}

Has CDM contributed to energy efficiency financing and implementation? Figure 11 shows that EE projects form a limited proportion of CDM markets, representing $15.2 \%$ of the proposed projects, but only $0.5 \%$ of the CERs delivered (UNEP/Risoe, 2010). There is a proportionally high rejection rate $(86 \%)$ of EE projects under the CDM process. This is of concern to developers, as the process is increasingly considered as tedious and highly uncertain. As such, the process discourages project developers from applying for such investments. CDM thus do not help trigger investments in EE. Furthermore, EE projects that end up generating CERs are mostly from the large industrial sector, not in end-use energy efficiency, a sector that remains largely untapped.

\footnotetext{
28 "Reductions in emissions that are additional to any that would occur in the absence of the certified project activity." Kyoto Protocol Article 12 paragraph 5.c. For more information on this issue please refer to Buchner, B. and P. de T'Serclaes, "How to trigger energy efficiency: The case for carbon finance?" (forthcoming).

${ }^{29}$ Over 18 accepted methodologies exist to date, as such they are limited to certain sectors and technologies.
} 
Figure 11: CDM projects by sector

Page | 44

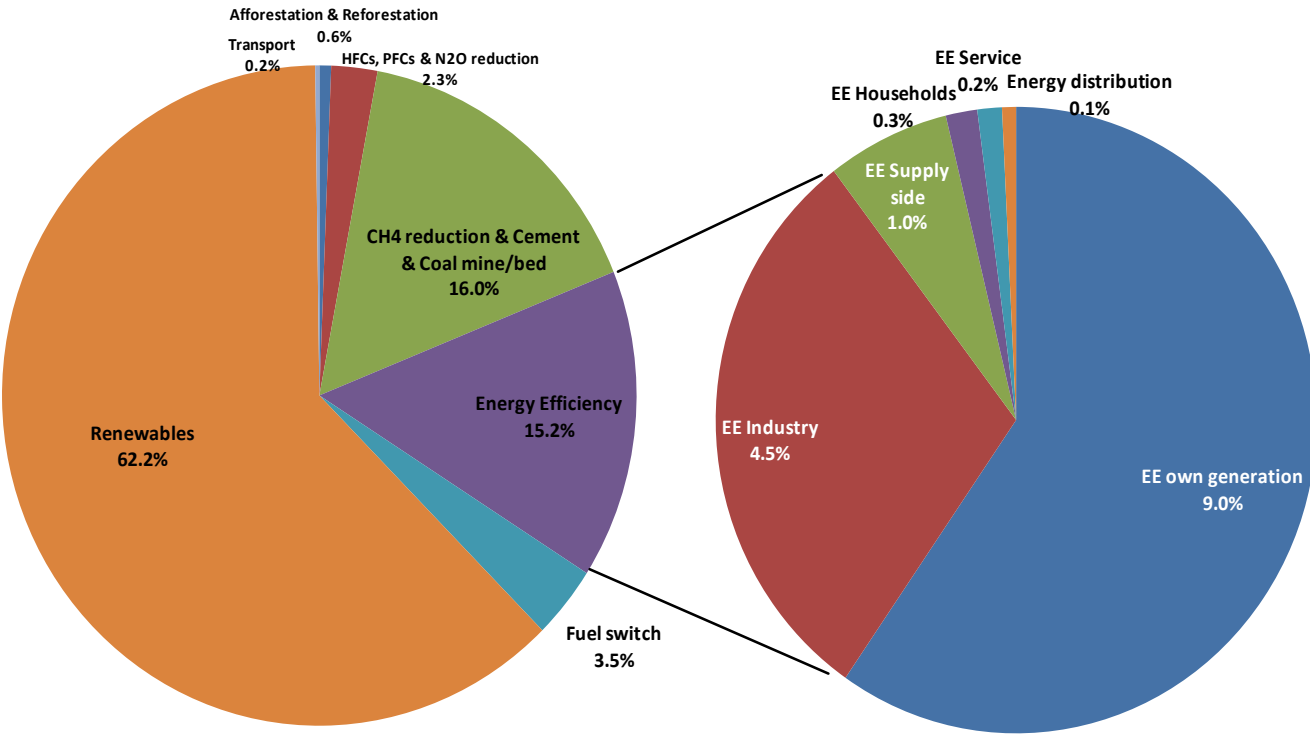

Source: UNEP/Risoe, 2009

\section{Lessons}

\section{CDM adds uncertainty}

To date, the CDM has not contributed to finance many EE projects and even less so for end-use EE projects; they represent less than $0.2 \%$ of all issued Certified Emission Reductions (CERs) (UNEP/Risoe, 2010). The complexities of the CDM approval process only increases the complexity and uncertainty of EE financing and result in higher transaction costs for project developers. In its current form, the CDM does not address risk perception or actual risks of EE projects.

The project-by-project nature of CDM monitoring and methodological application makes it illsuited for end-use EE projects. The small size and scattered nature of end-use EE projects, and potentially low generated income from CERs, often does not even cover the transaction costs should the project be accepted. Current methodologies prevent the crediting of capacity building, training or education, all essential elements to the creation of an enabling environment for private-sector financing of the EE end-use sector. Moreover, the absence of appropriate institutions to prepare CDM project proposals in the least-developed countries further increases the transaction cost for these countries and the geographical unevenness of EE projects in CDM. The recent executive board decision to accept deemed saving methodologies for some end-use technologies such as lighting appliances opens up some possibilities of improvement. Should these methodologies be adopted overall, they could provide the much-needed improvement in accreditation and certainty necessary for $\mathrm{EE}$ projects. ${ }^{30}$ However, this would require significant and long-term reforms.

\footnotetext{
${ }^{30}$ https://cdm.unfccc.int/public_inputs/2008/PoA/index.html
} 
Surveys and interviews reveal that most stakeholders have lost confidence in the utility of CDM to contribute to EE financing. Many project managers have been burnt more than once investing huge amounts of time and money trying to align projects - only to be rejected. The rejection rate of these projects is over $86 \%$. Independent consultants in India have pointed out the inappropriateness of using CDM for projects which make economic sense - and for which intervention should be targeted upfront, not at the end of the project.

Evidence from the surveys reveals that stakeholders in emerging countries are increasingly reluctant to consider CDM in financing energy efficiency. Having been disappointed at least once by the length and the uncertainties of the process, these stakeholders tend to shy away from the entire process.

It is not the purpose of the study to delve in too many details on possible reforms to the CDM; however, considering the absence of current carbon finance mechanisms, a few words will be said. The analysis shows that Annex I countries wish to tap EE improvement potentials in emerging economies - as IEA and IPCC analysis underline they should. Another mechanism or a reformed CDM will be needed to help do so. Proposals can be divided into proponents of a radically different architecture, and those who support incremental changes to the Kyoto Principles, a "beyond Kyoto" approach. ${ }^{31}$ As mentioned above, most of the criticism centres around the failure of the current mechanism to achieve emission abatement to the scale initially envisioned. Critics also point at the current scheme's focus on mitigation to the detriment of adaptation or sustainable development that will deal with climate change.

It has been argued that CDM needs to be more encompassing and should consider the importance of capacity building, training and education as well. As such the emphasis for the inclusion of nationally appropriate mitigation actions (NAMAs) within the scope of CDM is intensifying. There is no silver bullet solution to the challenges raised by the current CDM mechanism. The most serious proposals for reforms include simplification of the monitoring and verification process (which is quite challenging for end-use EE projects) as well as technologywide agreement (which would enable an ex-ante benchmarking of EE technologies). The call for Sectoral No-Lose Targets (SNLTs) or technology wide CDM would answer these preoccupations. The call for more emphasis on technology transfer would not apply to end-use energy efficient projects. Such reforms would be very well received by investors in EE projects: they will most likely lead to faster and surer validation of the projects. Such reforms would reduce uncertainties around CDM. The formalisation of deemed savings methodologies could set a benchmark of certification for EE projects and help reduce risk perception in energy efficiency. Such reforms might allow CDM to increase private EE financing, discussions, priorities around national mitigation action go in the same direction through measurement and other. Yet, these reforms are not implemented yet and will take a while to implement in action.

\section{Discussion}

The four instruments analysed in this section have all successfully contributed to (i) reducing risk associated with energy efficiency and (ii) triggering private sector's awareness and involvement in $\mathrm{EE}$ financing. The four cases underlined the importance of government intervention in creating an enabling environment. More specifically focusing on an increased private and public collaboration and creating reassuring market conditions for private investors has allowed the direct increase of private financing. Using various techniques, the risk-mitigation instruments developed by the IFC have allowed a similar increase of EE financing. The provision of a safety

\footnotetext{
${ }^{31}$ For more details on the criticisms and proposals for reform please refer to Adly, N. and Stavins (2008).
} 
net of first loss through loan guarantee programmes, as well as indirect training and education of the bankers, has raised commercial banks' interest in China. Today six banks are involved in the project and more are willing to join. In India, the introduction of training and capacity building programmes enabled an increase in private-sector interest.

The analysis of national mechanisms reveals that it is not necessarily very costly to leverage Page | 46 private investments; in effect, LPG disbursed almost no direct money unless the project defaulted (which has yet to happen in China). ${ }^{32}$ Similarly, the RF has been running for seven years with no cases of default, the only cost incurred by the government being the administrative supervision of the Fund. The international community is committing increasing amounts of money towards climate change mitigation. The years 2008 and 2009 saw the establishment of the Clean Investments Funds (CIFs) - committing an overall USD 6.7 billion of which USD 4.7 billion is for climate change mitigation. The UNFCCC and other institutions such as the Global Environmental Facility (GEF) are still providing channels for public and private sector investments towards climate change mitigation.

An emerging concern expressed by private investors is the need to increase information sharing and knowledge on EE financing. On several occasions in interviews, investors expressed the idea that the IEA should play a bigger role in disseminating the information. One professor at the Energy Research Institute in Beijing emphasised that "experts, training and capacity building are needed in China." Although the country has established high benchmarks for energy efficiency, adequate market infrastructure is still lacking. The technologies are there; what is needed is the service and implementation capacity. The risk aversion of financiers to end-use EE projects was again pointed out as a barrier. Investors also communicated a mistrust and wariness in EE technology.

The recent signing of a Memorendum of Understanding (MoU) between the Bureau of Energy Efficiency (BEE), the Hongkong and Shanghai Banking Corporation Limited and India (HSBC India) in this regard is very promising. Through this $\mathrm{MoU}, \mathrm{HSBC}$ commits to work in collaboration with the Indian government on the former Energy Efficiency Financing Platform (EEFP) to promote EE projects through the development of "risk-sharing strategies" as well as "capacity up-gradation of financial institutions" (news release announcing the signature of the MoU in March 2010). Although it is of course too early to gauge the effects of this initiative, it is a significant step in the right direction.

Figure 12: Identified successful risk mitigation instruments

\begin{tabular}{|c|c|c|c|c|c|}
\hline & Operational Risk & Technical & Monitoring & Regulatory & Financial \\
\hline $\begin{array}{c}\text { Energy } \\
\text { Efficiency }\end{array}$ & $\begin{array}{l}- \text { Failure of } \\
\text { the } \\
\text { technology } \\
\text { while in use }\end{array}$ & $\begin{array}{l}\text {-Difficulty of } \\
\text { quantifying } \\
\text { energy } \\
\text { savings } \\
\text { - Uncertainty } \\
\text { on savings }\end{array}$ & $\begin{array}{l}\text { - Uncertainty of } \\
\text { person capacity } \\
\text { to implement } \\
\text { technology } \\
\text { - Cost of M\&V }\end{array}$ & $\begin{array}{l}\text { - Uncertainty on } \\
\text { price of energy } \\
\text { - Uncertain } \\
\text { changes in } \\
\text { regulation }\end{array}$ & $\begin{array}{l}\text { - Uncertainty } \\
\text { on price of } \\
\text { energy } \\
\text { - Counterparty } \\
\text { risk }\end{array}$ \\
\hline $\begin{array}{c}\text { Risk } \\
\text { mitigation } \\
\text { instruments }\end{array}$ & $\begin{array}{l}\text {-IPMVP } \\
\text {-Contingency } \\
\text { financing } \\
\text { through risk } \\
\text { guarantee }\end{array}$ & $\begin{array}{l}\text {-IPMVP } \\
\text {-Contractual } \\
\text { arrangements } \\
\text {-Liability } \\
\text { insurance }\end{array}$ & $\begin{array}{l}\text { - Capacity } \\
\text { building/awareness } \\
\text {-Money for M\&V, } \\
\text { systematic data } \\
\text { collection }\end{array}$ & $\begin{array}{l}\text { - More } \\
\text { certainty in } \\
\text { reforms } \\
\text {-Consistency }\end{array}$ & $\begin{array}{l}\text { - Uncertainty } \\
\text { on price of } \\
\text { energy }\end{array}$ \\
\hline
\end{tabular}

\footnotetext{
${ }^{32}$ This does not account for indirect human capital cost of training and accompanying, which are of course significant.
} 
Section 2 has gauged the relative success of selected international and national mechanisms in meeting the criteria to the scaling up of EE financing. The evaluation confirmed the results from interviews and underlined key elements of success: improved information channels through PPP or training and capacity building programmes, as well as direct-risk mitigation through contingency financing, increased private sector involvement in EE financing. Figure 12 highlights the most successful tools for mitigating risks.

Despite the identified success stories, analysis of the general macro data has also confirmed that these CDM mechanisms are not enough to trigger adequate levels of private investments. Although private EE financing and public investments are rising, the energy efficiency investment gap is still very wide. Which turns us to government need to reconsider their roles in EE financing: What could they do? Where should they focus their attention to trigger private financing? The next section discusses policy implications of the case study findings for governments, as well as the role that the private sector should adopt, to allow the development of creative financing to fill the gaps. 



\section{SECTION 3: Policy discussion and recommendations}

The national and international case studies described in the previous section illustrate how EE investment can be increased by addressing perceived risks. This section recommends government policies that can trigger a sustainable virtuous circle of EE investments. Figure 13 illustrates our recommendations for government actions to create such a virtuous circle. In particular governments should focus on aligning incentives and reducing the gap in risk perception, thereby allowing the private sector to recapture the missed market opportunity through creative financing.

Figure 13: Triggering a virtuous circle of sustainable EE investments

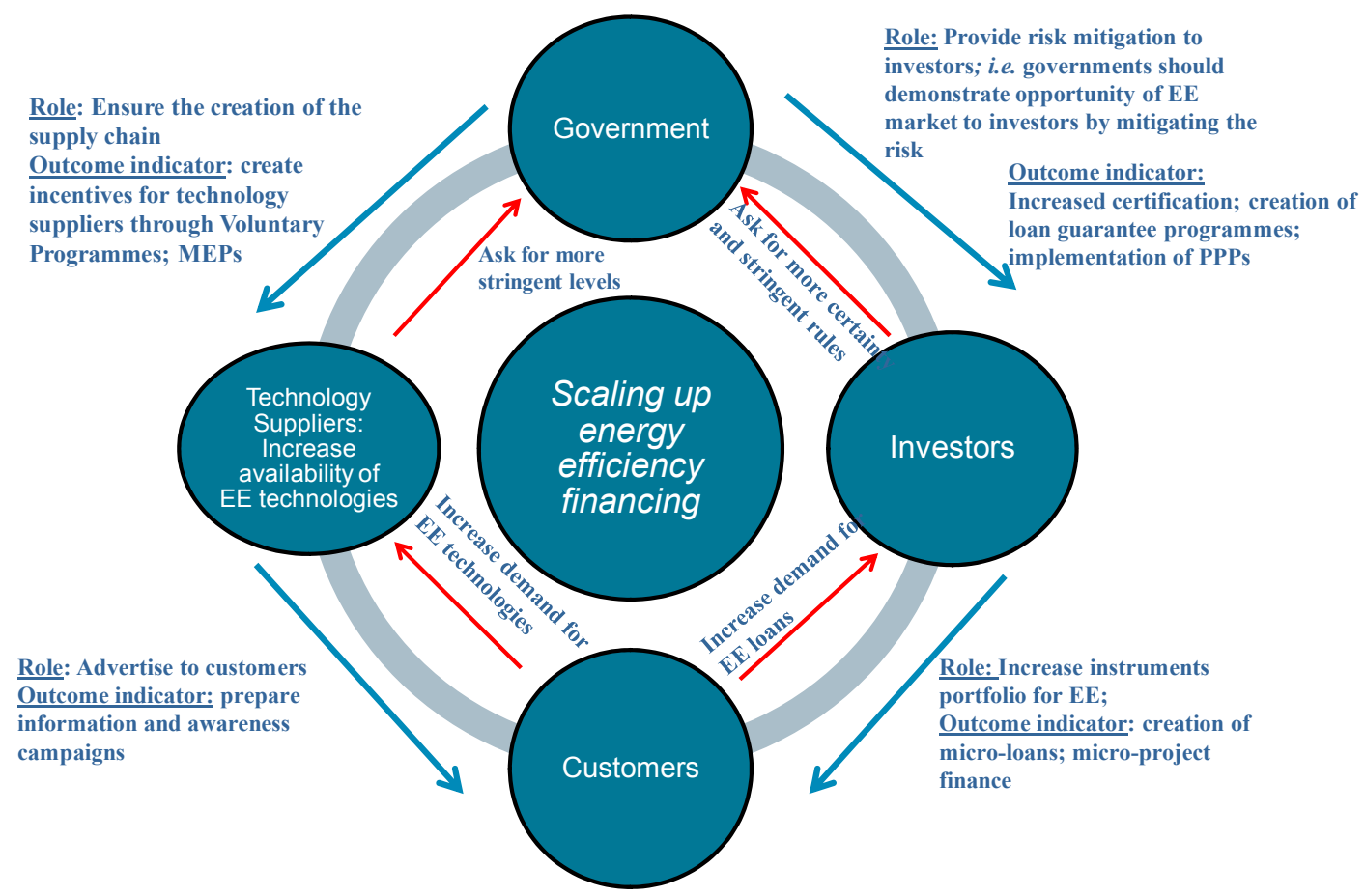

\section{The role of the private sector: seizing business opportunity through creative financing}

Establishing firm international and national public commitment to EE financing opens up the possibilities of creative financing by the private sector. EE projects could become commodities that can be traded against oil price fluctuation; e.g. as a hedging instrument. A European Investment Bank (EIB) employee points out that "the finance is not necessarily the problem, what the private sector needs are enablers. Public finance could be used to credit enhance projects." 


\section{Energy efficiency as an insurance mechanism}

Once the risk perception is tackled, traditional insurance mechanisms could be implemented to deal with the different risks faced by EE projects. These projects are subject to physical risks internal to the project such as the actual performance of a given technology or the operational maintenance of the project. Economic risks relating to uncertainties on measurement and monitoring of the savings are also important. Different risk management options are available for the different types of risk, such as hedging instruments (fixed-price contracts, risk-based rates hedges, etc.). Applying traditional risk management instruments to deal with the uncertainty surrounding energy efficient projects could mean using one of two solutions: (i) energy saving insurance (ESI) and (ii) surety bonds.

ESI are a formal risk transfer from the promoter (ESCO or other) to an insurance company pending payment of a premium. In exchange for a premium, the insurer agrees to pay any shortfall in energy savings below a pre-agreed baseline, less a deductible. ESI has traditionally been used for existing buildings that are retrofitted to achieve savings. Several insurers are now investigating applications to new buildings where a logical baseline (such as existing energy codes) can be defined. Surety bonds on the other hand do not transfer the risk fully. The estimated market potential for these instruments is huge. Mills et al. (2006) estimate the US market for ESI to be around USD 1 billion per year in premium income. ${ }^{33} \mathrm{ESI}$ offers a number of potential benefits in terms of an energy-policy perspective: (i) ESI transfers performance risk from the balance sheet of the entity implementing, the energy savings project, thereby freeing up capital otherwise needed to "self-insure" the savings; (ii) ESI reduces barriers to market entry of smaller energy services firms who do not have sufficiently strong balance sheets to selfinsure the savings; (iii) ESI encourages those implementing energy saving projects to go beyond standard, tried-and-true measures and thereby achieve more significant levels of energy savings; and (iv) ESI providers will also naturally become promoters of improved savings measurement and verification techniques, which will, in turn, benefit others.

Surety bonds are three-party contracts between the insurer (A), contractor (B) and property owner $(C)$ covering both the construction phase and the revenue stream. If $B$ does not perform (i.e. there is a technical or performance failure and energy savings are not achieved), then $B$ needs to pay A back. During the construction phase, the bond becomes an insurance tool insuring that the project can be completed for a particular price (i.e. like in the case of call and put). ${ }^{34}$

In both cases, a high potential liability falls on B. As such, the contractor needs to demonstrate strength and show solid balance sheets. This is precisely where the shoe pinches: most contractors will not have strong enough balance sheets to cover potential losses and as such fail to qualify. ${ }^{35}$ As such surety bonds provide only limited risk transfer, both in scope and in the areas covered, they would apply only to construction projects, not retrofitting. Moreover, they will not cover small-scale project developers who are most in need of insurance and guarantee.

\footnotetext{
${ }^{33}$ Assuming premiums equal to 3 percent of savings.

34 "Many projects in state-owned facilities require surety bonds. Pricing is typically $1 \%$ of the project cost or stipulated savings, with a wide range $(0.1 \%$ to $1.5 \%)$ depending on the caliber of the bond purchaser. One example identified bond costs for a USD 200 000/year energy saving guaranty (USD 1.8 million cap cost project) were USD 3000 to USD 4000 annually (1.5\% to $2 \%$ of the project's lifetime savings)." Mills (2001) http://repositories.cdlib.org/lbnl/LBNL-48927

${ }^{35}$ Another instrument that we have not considered are savings guarantees where energy managers are self insured, i.e. retain the risk internally rather than selling the risk to a provider of insurance bonds.
} 
More generally, risk transfer mechanisms and instruments from the insurance industry are good areas to explore solutions for EE markets. The case of risk-guarantee mechanisms have led to sustainable changes by granting local financial stakeholders time to familiarise themselves with the specificities of EE project financing and learn the technicality required. Work and research still needs to be done concerning adequate pricing policy; i.e. how much premium will be justified, and should part of this premium be covered by the government (or an international mechanism)? This is why an adequate quantification of technical risk in terms of monetary value will still be necessary. Another key challenge will be finding means to cover the entire uncertainty spectrum of EE projects. ${ }^{36}$ These solutions are only just emerging for mature economies, and will likely be difficult to apply in emerging economies where markets are less mature - both financially and in terms of energy management. Thus, insurers are likely to apply a much higher premium, which will most probably end up being detrimental to the project developer. (Other possibilities include the creation of insurance mechanisms against high climate risks, securitisation based on EE tranches, etc.) By contrast, a private investor ${ }^{37}$ underlined that "public institutions will never replace the commercial/private sector; what we need are public insurance mechanisms to address certain risks." Private investors were also adamant that public financial institutions should not supersede private investors. There are instances in which public financial interventions will be welcomed in the risk mitigation; but this does not mean that all risks should be handled through public institutions. Far from it. Investors consider they are better placed to handle such things as investment risks and technical risk. As long as a project has an attached financial value, the market can handle the risk. In that sense, the public financial role should focus on establishing this financial value.

In all instances, governments need to focus on aligning incentives and reducing the risk perception to allow this secondary market of creative private-sector financing to take over. The first pilot projects using such instruments offer interesting prospects to cover parts of the risk. They deserve to be taken seriously and more analysis should be made concerning the potential market creation should they be applied worldwide. However, they are no silver bullets: they cannot be expected to cover the entire range of risks characterising EE projects and they will be particularly difficult to implement in emerging economies where financial and energy markets are far from being mature.

\section{Securitising energy efficiency: EE derivatives as a hedging instrument against high fuel prices, climate change damage?}

Although the recent subprime crisis has undermined the benefits of securitisation, there is no reason to doubt that EE projects could ultimately become an important securitisation market. The creation of favourable conditions for private-sector involvement in EE financing opens possibilities for structured financing of energy efficiency. Another structured product would see the application of actuarial pricing models to EE projects: i.e. bundling EE projects and using them as hedging instruments against the volatility of fuel prices. The ultimate aim would be to transform energy efficiency into a tradable commodity. This approach was briefly implemented by Enron in the late 1990s. Enron Energy Services (EES) focused on leveraging its expertise in risk management to sign commodity deals, namely contracts for the supply of retail electricity and natural gas. Actuarial pricing would translate physical realities and potentials into income streams. Such an approach would mean the elaboration of an actuarial database, pricing curves

\footnotetext{
${ }^{36}$ Future work should look more closely at quantifying these risks.

${ }^{37}$ Renewable financing conference IEA/OECD, March 2010.
} 
and a pricing process compatible with commodity pricing. As mentioned in the previous section on the importance of certification, the implementation of a certification protocol allowing the translation of different physical realities in financial expectations would enable EE projects to be used as hedging instruments against high fuel prices for instance, or against major climate catastrophe.

Page | 52 The main advantage of such approach would be to open up energy efficiency to a significantly increased secondary market. Insurers could both sell EE investments to their clients having to fulfil a given target or for them as guarantees against major climate catastrophe. Estimates along this line consider that this could lead to the emergence of a USD 453 trillion market (Mathew et. al., 2005). The emergence of a secondary market for EE financing will not happen without stimulus. Creative financing is only part of the solution. It will need the prior establishment of stable institutional capacity building (in this case strong certification and monitoring institutions), as well as increased information sharing and training of the private sector. The study recommends the establishment of an Energy Efficiency Financial Action Network (EEFAN).

The post-subprime crisis is making those prospects more doubtful for the near future, since both investors and the public are wary of structured derivative products at this time. However, this same crisis context has lead to increased interest in EE projects through the injection of unprecedented amounts of money via stimulus packages, and as such also represents a great opportunity to collaborate more closely between the private and public sector. Now is the time for governments, policy makers and the private sector to work together to establish a risk management protocol that allows the translation of EE physical realities into financial investment opportunities. Although public and private dialogue has increased, it needs to be further expanded and systematised to establish a new market.

The economic meltdown has also underlined the importance of combining "green" with economic development. Rather than being seen as an obstacle, the current financial crisis should be seen as an opportunity for a paradigm shift: moving away from considering energy efficiency as a liability, and instead starting to view it as a hedging insurance tool that could be used against price volatility of petrol, for instance. Such a paradigm shift could lead to the emergence of an unprecedented reassurance market.

Yet, allowing such change calls on strong public commitment to create enabling environments that are attractive to the private sector. As such the study makes four key conclusions, discussed below.

\section{The role of governments}

Based on evidence and analysis, the study makes four main recommendations:

- Governments need to increase data gathering, information sharing and training, including a platform for continuous public/private dialogue.

- Policy makers should focus on tools that reduce the perceived risk of EE projects.

- An international monitoring and evaluation protocol needs to be implemented.

- Finally, more work is needed to determine the best combination of financial and other instruments (such as training, education, capacity building or awareness building) for reducing high levels of perceived risk. 
The need for increased information sharing and capacity building was iterated by many stakeholders in interviews. As such, the study calls for the creation of an Energy Efficiency Action Network (EEFAN), ${ }^{38}$ an international platform to enable regular co-operation and information sharing between the public and private sectors. The absence of micro-level data on energy use and investments significantly undermines policy-makers' abilities to take informed decisions and implement most effective policies. This study was able to provide insights into the realities of EE markets by conducting a series of surveys and one-on-one interviews with financial institutions and stakeholders in the market. More generally, the IEA is already tracking IEA countries' progress regarding the implementation of EE recommendations through its progress reporting (i.e. self evaluation and implementation from the countries). However, this is not enough. There is a clear lack of information on the level of investment flows shared across different kinds of investments, as there is a lack of information concerning the evolution of energy consumption patterns at a micro level - even more so in emerging economies. The survey underlines the willingness of the private financial sector to receive training in energy efficiency. Results moreover underlined the importance for private financial institutions to get more insights and pre-emptive information into the evolution of regulatory issues. The creation of EEFAN would be useful in both instances.

Increased information will allow the private sector to be both more aware and reassured on EE investments. Governments should focus their efforts on financial instruments that guarantee EE projects that allow addressing such risk perception. In the short term, this calls for the adequate disbursement of guarantee resources by the public sector through loan guarantee programmes (LGPs). Evidence from the case studies in China show that this form of contingency financing can help leverage private money up to four times the amount of public money invested.

In the longer term it calls for an international harmonisation of monitoring and verification $(\mathrm{M} \& \mathrm{~V})$ protocol in an attempt to decrease risk perception and actual risks of EE projects. Maintaining a contingent financing facility is administratively costly even if the facility never disburses. In the longer term, the need for increased certainty through financial instruments could be replaced by the establishment of an international M\&V protocol - backed up by relevant stakeholders - which would establish firm expectations for end-use EE technologies. Such a framework would allow the safe translation of uncertain technological potentials into certain investment stream of benefits. Further work on risk perception could help develop a programmatic approach to which combinations and sequences of financial instruments, public/private partnerships, and capacity building provide the best leveraging of private investment in the most cost-effective way.

The implementation of the suggested recommendations by national governments and international donors should allow the private sector to see the investment opportunity and modify existing financial tools to suit EE projects. The implementation of these recommendations implies considerations for international initiatives currently under development, as well as ongoing discussions on CDM reforms. The recent development of the Clean Technology Funds (CTF) and the International Energy Efficiency Financing protocol (IEEFP or the Protocol) holds great potential for increased EE implementation.

\footnotetext{
${ }^{38}$ More details on this proposal are provided throughout the study. In addition, a summary of the proposal is attached in the annex.
} 


\section{Implementation of these recommendations at the international level}

\section{International Energy Efficiency Financing Protocol (IEEFP)}

As observed in the first section of this study, the difficulty and level of technical understanding required to translate expected energy savings into expected incoming cash flows is one of the reasons investors still feel wary of EE investments. End-use EE projects usually end up being very technical for small profits. The transaction cost is therefore too high. However, this need not be the case. The clear benchmarking of known technologies, as well as risk mitigation options, could translate into a set of expected stream cash flows that would reassure investors to move forward with investment decisions.

The IEEFP has been established to provide guidance and benchmarks for local financial institutions in emerging economies. Published in April 2009, the IEEFP was developed by the Efficiency Valuation Organization (EVO) as a reference document for local financial institutions wanting to put in place EE projects. ${ }^{39}$ After a brief summary of the main challenges and risks faced by local financial institutions, the Protocol presents a list of common EE technologies and their expected savings. The Protocol also provides a small number of case studies illustrating the financial returns contractors can expect from the implementation of different technologies. ${ }^{40}$

\section{Potential achievements}

A potentially very promising tool, the IEEFP could help familiarise local financial banking personnel with EE investments. However, it would benefit from explaining in more detail the range of solutions and the reflexes that financiers should have when facing certain situations. ${ }^{41}$ The Protocol should be commended for providing a first and important step towards the mainstreaming of energy efficiency, but it does not represent the panacea. A more systematic listing of all technologies would be needed to eliminate uncertainty surrounding EE projects. More training, advertising and awareness campaigning will be needed, along with more examples and more systematic translation of the technology's potential in terms of revenue streams.

In its present state, the Protocol still needs to expand its technological scope: not enough technologies are covered. It should also be broadcasted worldwide. It has only been published quite recently, a real outreach effort is needed to ensure the Protocol (or similar document) stands as a reference for the different stakeholders, particular by those at the highest levels. The Protocol has yet to provide deemed savings methodologies for the maximum number of technologies, and get better known by private financial institutions.

The IEEFP provides a first step towards improving investors' understanding of EE projects. By providing a range of risk mitigation options, and different financial structure examples underlining that the best approach is one of adapted project finance - the Protocol simplifies the technicality of efficiency projects and make them more accessible to bankers. By providing more information and broadcasting successful cases, the Protocol could help build the case for EE financing, but at this stage it is still a work in progress and needs to be completed and accepted by private investors.

\footnotetext{
${ }^{39}$ For more details please refer to www.evo.org

${ }^{40}$ For more information please refer to www.evo-world.org

${ }^{41}$ The protocol has emerged out of on-the-ground experiences - and a series of workshop which among other things revealed the total lack of awareness from financiers on the opportunities of energy efficiency market.
} 


\section{Climate Investment Funds (CIF)}

\section{Process}

Climate Investment Funds (CIF) have recently been created in an effort to fill a potential gap before a new post-Kyoto financial architecture is established. The CIF comprises the Clean Technology Fund (CTF) and the Strategic Climate Fund (SCF). The CTF seeks to fill a gap in the international architecture for development finance by offering more concessional rates than standard terms used by multilateral development banks (MDBs). It aims at scaling up financing to provide incentives for developing countries to integrate nationally appropriate mitigation actions (NAMAs) into sustainable development plans and investment decisions. The CTF main areas of focus are: deployment and transfer of low-carbon technologies in the power sector; transportation; and energy efficiency in buildings, industry and agriculture. The SCF provides financing to pilot new development approaches or to scale-up activities aimed at a specific climate change challenge through targeted programmes. The first programme to be included in the SCF would pilot national level actions for enhancing climate resilience in a few highly vulnerable countries. Other projects under consideration include: support for energy efficient and renewable energy technologies to increase access to "green" energy in low-income countries; and investments to reduce emissions from deforestation and forest degradation through sustainable forest management (World Bank, 2009). The Funds are meant to serve as an interim measure while negotiations continue.

On 1 July 2008, the World Bank Executive Directors approved the creation of the Climate Investment Funds; and on 26 September 2008 donors gathered to pledge over USD 6.1 billion. As of 31 January 2010, USD 4.7 billion have been committed through the Clean Technology Fund - responsible for climate change mitigation - among which USD 292 million towards scaling up renewable energy, and no defined amount for energy efficiency. The CIFs are managed by the World Bank and implemented jointly.

The financing products of the CTF are defined as followed:

Outgoing financing from the CTF can be no more concessional than incoming financing.

- Grant contributions may be used to finance grants, concessional loans and other financial products, such as guarantees;

- Capital contributions may be used to finance concessional loans and other financial products, such as guarantees;

- Loan contributions may be used to finance loans and other financial products, such as guarantees, on terms no more concessional than the terms of the contributions. ${ }^{42}$

\section{Potential achievements}

It is too early to evaluate the impact of the CIF. Analysing one of CTF projects - such as the Thailand Investment Plan - shows that the biggest allocation of the money is going towards renewable products. Although the plan does mention the importance of energy savings and energy management programmes, most of its financing programmes target the renewable sector. However, promises of increasing the financing - including through contingency financing

\footnotetext{
${ }^{42}$ Clean Technology Fund: Financing products, terms, and review procedures for public sector operations", May 2009.
} 
- of EE projects and technologies are made. It remains to be seen whether these are indeed implemented.

The Funds should be commended for moving away from mere concessional loans to more refined instruments such as loan guarantee programmes in collaboration with local multilateral development banks (MDBs) in a recent effort to promote EE programmes. They are only meant

Page | 56 to stand as an intermediary vehicle until agreement is reached on the nature of the financial architecture.

Should the Funds survive longer than planned (in the event of an international failure to strike an agreement on future financial architecture), this study urges policy makers to consider identified criteria of success in the creation of a virtuous circle for EE investments. 


\section{Summary and way forward}

A great potential of energy efficiency in emerging economies is still untapped. The EE investment gap is still tremendous. For incremental needed investments estimated at over USD 299.4 billion yearly, a conservative view estimates current public investments going towards energy efficiency at USD 9-11 billion. While public international investments for climate mitigation are continuously rising, private-sector investments are still lagging behind. Analysis undertaken in the development of Money Matters identifies very real barriers to accessing financing on the part of project developers, but then also looks at the non-financial barriers particularly the perception of risk associated on the part of investors.

Money Matters starts by analysing the challenges faced by two emerging economies - China and India -in financing energy efficiency. These countries were chosen not only because their economies are emerging, but also because they both have achieved a relative decline in energy intensity over the past decade. It should be noted, however, that this decline is a consequence of their booming economic growth, more than a reflection of dramatic improvements in energy efficiency. While this paper's findings reflect the experience of investors and project developers in these two countries, it is anticipated that other emerging and non-emerging economies can draw lessons from the experience of China and India.

\section{Financing challenges}

Higher sovereign risks, as well as specific banking structures that may sometimes be inadequate to foreign investors or institutional frailty, all constitute new challenges to the financing of EE projects. Such challenges only add to the original difficulties of financing energy efficiency.

Section 2 of Money Matters identifies policies and measures that have helped overcome financial barriers to end-use EE projects. Contingency financing for instance provides a risk guarantee to local commercial banks which can be used in cases of default. It can take the form of a safety cushion or a direct cash injection as an equity stake. Increased public/private collaboration can also contribute to investment risk-hedging and confidence-building in investors.

Institutional reinforcement and the modification of certain rules and provisions have also gone a long way in facilitating access by foreign investors in end-use EE projects. Here Chinese eradication of the confiscatory fiscal policy comes to mind, since it allowed higher foreign investments.

Evidence similarly suggests that stakeholders from the EE world are looking for increased guidance from government before scaling-up private investment in energy efficiency. In fact, what is needed is government willingness to create favourable environments for private sector financing. This in turn will provide an opportunity for creative financing, and could open the door to secondary market investments - through insurance mechanisms, securitisation of EE savings, or other tools not yet exploited. Although end-use EE projects are small individually, they represent a large market opportunity when aggregated. The implementation of the suggested recommendations by national governments and international donors should allow the private sector to see the investment opportunity and modify existing financial tools to suit EE projects. 


\section{Is money ALL that matters?}

Money Matters demonstrates that money alone is not the issue. Evidence, both theoretical and factual, underlines that the gap between risk perception and actual risk is still a strong deterrent to higher involvement by the private sector. The uncertainty surrounding expected energy Page $\mid 58$ savings, as well as the small size of individual end-use EE projects, their high technicality and scattered nature, all contribute to deter investors. Investors tend to view EE projects as too much hassle for too little profit.

In general, governments should target their money and expertise towards the reduction of the perception gap, thereby allowing the private sector to take over. Instruments targeting the misperception of risk such as loan guarantee programmes (e.g. those implemented by the IFC/GEF programme in China) are quite successful in meeting these risk mitigation goals, at least in the short term. In the longer term, the establishment of international measurement and verification protocol - which would support translating technological potentials in monetary terms - should be encouraged to reassure and facilitate the private sector's involvement in enduse EE projects. Targeting public resources towards better leveraging of private resources is what matters.

This is not to say that public institutions should cover all the risk: much to the contrary. Private financial markets are much better placed to handle some of the actual risks. Surveys revealed that private financial stakeholders were eager for more training, information sharing and best practice exchanges on EE financing. EE capacity building in the local context needs to be increased. Local bankers as well as project developers need to be trained in the technicalities of EE projects.

Clearly, the public and private sectors need to work together to align their strengths toward overcoming the risk-perception barriers identified. The development of awareness campaigns, or the establishment of public-private partnerships between multilateral development banks (MDBs) and local commercial banks, enabled local stakeholders to be trained in the specificities of EE technologies, thereby reinforcing trust in these projects.

\section{The importance of timing in EE financing}

The current economic crisis is likely to have two main effects on the evolution of EE investments. First, by temporarily reducing energy demand, it wrongly downplays the importance and urgency of triggering the efficiency revolution. Second, finding money for EE projects is likely to become even more difficult than before, and since investors are less likely to take on risk than before the crisis, finding ways to deal with uncertainty and risk mitigation are all the more important.

The analysis of the clean development mechanism (CDMs), the current international mitigation instruments recognised by the UNFCCC for private investments in the clean energy of emerging economies, has shown a low success rate in tapping EE potentials. Brief analysis of CDM breakdown reveals that significant reform was needed for the scaling-up of EE financing. Additional commitments such as the Clean Technology Funds (CTF) are commendable, but still insufficient.

Capturing the remaining EE potential is within our grasp. The timing however is crucial. Governments should seize the opportunity of current economic meltdown to pave the way for 
private sector involvement in EE financing. Evidence in the study identified successful tools: what is needed now is political commitment towards their implementation.

Evidence from this study suggests that instruments exist - both financial and non-financial to overcome the perceived higher risk associated with EE investments. Three instruments in particular - risk guarantees, training and education, and increased public-private sector collaboration - have proven effective and to a certain extent both substitutable and reinforcing. For example, training and education (including data and information sharing) increases capacity among investors and lenders, especially in emerging economies.

What is needed is government willingness to create favourable environments for private-sector investments. This will provide an opportunity for creative financing. It could open the door to secondary market investments through insurance mechanisms, securitisation of EE savings or other tools not yet exploited. Although end-use EE projects are small individually, they represent a huge market opportunity when aggregated.

The study recommends the following actions on the part of the public and private sectors, in some cases, requiring joint effort: ${ }^{43}$

- Public and private sectors should collaborate to increase data gathering, information sharing and training, including a platform for continuous public-private dialogue. The study calls for the creation of an Energy Efficiency Action Network (EEFAN) ${ }^{44}$ to serve as an international platform to enable regular co-operation and information sharing between the public and private sectors.

- Policy makers should focus on tools that reduce the perceived risk of EE projects.

- Governments should work together to implement a harmonised, international monitoring and verification protocol in order to reduce both risk perception and the actual risks of $\mathrm{EE}$ projects.

- Together, the public and private sectors should undertake additional studies to determine the best combination of financial and other instruments (e.g. training, education, capacity building or awareness building) to reduce high levels of perceived risk. Such studies could develop a more programmatic approach to determining which combinations and sequences of financial instruments, public-private partnerships and capacity building provides the best and most cost-effective leveraging of private investment.

\footnotetext{
${ }^{43}$ This is not to suggest that these four recommendations will address all barriers to EE projects. Governments will still have to face the challenge of covering the upfront costs of EE projects in cases in which parts of the population cannot cover such costs. One potential mechanism would be the establishment of micro-project finance for energy efficiency. As explained in de T'Serclaes (2007), the closest financial structure to financing such projects would be project finance that relies on future revenues of cash flows to finance an investment. Traditional project finance structures imply high transaction costs to evaluate adequately the ins-and-outs of the project. A complete risk evaluation and feasibility study of the project is conducted before any finance is actually committed. The typical deal structure of project finance revolves around USD 30 million, much higher than any of the deals currently structured for EE financing.

${ }^{44}$ Although more details on this proposal are provided throughout the study, a summary of the proposal is attached in the annex.
} 


\section{References}

Aldy, J. and Robert N. Stavins (2007) Architectures for Agreement: adressing global climate change in the post-kyoto world Cambridge University Press, Cambridge

Page I 60 Bureau of Energy Efficiency (BEE, 2008a), "India: Manual for the Development of Municipal Energy Efficiency Projects"

Bureau of Energy Efficiency (BEE, 2008b), "SME Status and Way Forward" presentation by Jitendra Sood

Bureau of Energy Efficiency (BEE, 2010)

Carmody, Josh (2009) Personal Conversations

Chandler, William, and Holly Grin (2008), 'Financing Energy Efficiency in China', Carnegie Endowment for International Peace.

Deutsche Bank Research (2005), 'China \& India: A visual essay', (http://www.dbresearch.com/PROD/DBR_INTERNET_EN-PROD/PROD0000000000192108.pdf).

Global Environmental Facility (GEF) (2006). UNDP-GEF Fuel-Cell Bus Program: Update. GEF Council.

Government of China, Ministry of Finance (MOF) (2008), 'Report on the Implementation of the Central and Local Budgets for 2007 and on the Draft Central and Local Budgets for 2008', (First Session of the Eleventh National People's Congress, March 5, 2008 edn.).

Government of China, Ministry of Finance (MOF), and the National Development Reform Commission (NDRC) (2007), 'Notice on the Issuance of 'Energy Saving Technological Transformation of Financial Incentives' Interim Procedures for Fund Management', http://www.mof.gov.cn/news/20071219_3460_29945.htm.

Government of India (GOI, 2006) XIth Plan Proposals for New and Renewable Energy Delhi in Government of India Ministry of New and Renewable Energy

Government of India (GOI, 2008a), 'National Action Plan on Climate Change', in Prime Minister's Council on Climate Change

Government of India (GOI, 2008b), Submission on Financing Architecture for Meeting Financial Commitments under the UNFCCC

Government of India (GOI, 2008), Ministry of Power, Bureau of Energy Efficiency 'Accredited energy service companies (ESCOs)'

Haites, Erik (2008) "Investments and Financial Flows Needed to Address Climate Change" for Breaking the Climate Deadlock

IEA (2002), Electricity in India: Providing Power for the Millions Paris: OECD/IEA.

IEA (2003), Creating Markets for Energy Technologies Paris: OECD/IEA.

IEA (2007a), Mind the Gap - quantifying principal-agent problems in energy efficiency. OECD/IEA, Paris.

IEA (2007b), IEA energy efficiency policy recommendations to the G8 Summit Paris: OECD/IEA. 
IEA (2008a) Promoting energy efficiency investments - case studies in the residential sector Paris OECD/IEA/ AfD

IEA (2008b), Energy Technology Perspectives Paris: OECD/IEA

IEA (2009) World Energy Outlook Paris: OECD/IEA

IEA (2010a) Energy Technology Perspectives; Paris: OECD/IEA

IEA (2010b) IEA statistics

Lefevre, N., Philippine de T'Serclaes and Paul Waide (2006) "Barriers to technology diffusion: the case of compact fluorescent lamps", Paris AIXG/OECD/IEA

Levine, M (2005), 'Energy Efficiency in China: Glorious History, Uncertain Future', Energy Resources Group Colloquium, Febuary 92005 (University of California, Berkeley).

Lovins, A. (2007) "Energy Myth Nine - Energy Efficiency Improvements Have Already Reached their Potential," in Energy and American Society - Thirteen Myths, ed. Benjamin K.Sovacool and Marilyn A. Brow; New-York, Springer

Mathew, P., Stephen Kromer, Osman Sezgen and Steven Meyers (2005), "Actuarial pricing of energy efficiency projects: lessons foul and fair" in Energy Policy Volume 33 Issue 10

McKinsey (2008) "How the world should invest in energy efficiency" The McKinsey Quaterly, Economic studies

McNiel, Michael, Maithili Iyer, Stephen Meyers, Virginie Letschert, and James McMahon (2008), 'Potential benefits from improved energy efficiency of key electrical products: The case of India', Energy Policy, 36, pp.3467-76.

Menkhoff, Lukas, Doris Neuberger, and Chodechai Suwanaporn (2006), 'Collateral-based lending in emerging markets: evidence from Thailand', Journal of Banking and finance, 30, 1-21.

Mills, E. (2001) "Risk transfer via energy-savings insurance", Lawrence Berkeley National Laboratory

Mills, E., Steve Kromer, Gary Weiss, and Paul A. Mathew (2006) "From volatility to value: analysing and managing financial and performance risk in energy savings projects" in Energy Policy 34

Sathaye, Jayant, Stephane de la Rue du Can, Satish Kumar, Matihili Lyer, Christie Galitsky, Amol Padhke, Michael McNeil, Lynn Price, Ranjit Bharvirkar (2006), 'Imlementing End-use Efficiency Improvement in India: Drawing from Experience in the US and Other Countries', LBNL, LBNL-60035.

Slovic, P., Baruch Fischhoff, and Sarah Lichtenstein (1982) "Why Study Risk Perception?" in Risk Analysis Vol.2 No.2

Sturm, Russel (IFC) Personal Conversation. Conference, May 2006

Sunstein, Cass R. (2007), 'The complex climate change incentives of China and the United States', AEI-Brookings Joint Center working paper 07-14 http://ssrn.com/abstract=1089143.

Taylor, Robert; C., Govindarajalu; Levin, J.;Meyer,A.; Ward, W. (2008), Financing Energy Efficiency: Lessons from Brazil, China, India and beyond (Washington: The International Bank for Reconstruction and Development/The World Bank). 
de T'Serclaes, P. (2007) "Financing Energy Efficient Homes: existing policy reponses to financial barriers" OECD/IEA, Paris

de T'Serclaes,P.; E. Gasc and A. Saussay (2009) "Financial Crisis and Energy Efficiency" OECD/IEA, Paris

UNEP-Risoe (2010), 'The Kyoto Protocol, the clean development mechanism, and the building and construction sector', UNEP Risoe.

UNEP-SEFI (2008), 'Public Finance Mechanisms to Mobilise Investment in Climate Change Mitigation'.

Ward, Murray (2008), 'A New Scaling up Mechanism For Developping Countries', in UNEP Risoe (ed.), A reformed CDM--including new Mechanisms for Sustainable Development (Copenhagen: UNEP Risoe).

World Bank (2009), Clean Investment Funds) "Clean Technology Fund: Investment Plan for Thailand"

World Ressource Institute (2009) Powering up: the Investment Potential of Energy Service Companies in India Washington/DC 


\section{Annex A: Methodology for the collection of public data}

In Tirpak \& Adams (2008) the authors use official development assistance (ODA) data from the Creditor Reporting System (CRS) database of the Organisation for Economic Co-operation and Development (OECD).

The original data were reported by bilateral donors who include the 22 members of the OECD's Development Assistance Committee (DAC) and the European Commission (OECD, 2007). The objective of the CRS is to create a comparable reporting basis for all DAC members through the use of common guidelines and definitions. Data from multilateral organizations were obtained directly from those institutions, since they are not obliged to report to the OECD. This article does not cover aid activity comprehensively. Not all donors supply data to the OECD. The coverage of donors' activities varies over time, although activity data have been more complete since 1999. Reporting of data may be influenced by staff changes in aid agencies, and may often be subjective, despite adherence to the guidelines. The major gaps in coverage post-1999 in official bilateral development assistance reporting come from Japan and the European Commission. The former does not report technical co-operation activities, while the latter does not report activities financed through the budget of the European Commission. Information on data quality indicators and a list of DAC members can be found in the CRS online User's Guide. Within the CRS database, aid activities are recorded on the basis of commitments according to a 'marker' system that identifies the purpose of the aid. For DAC purposes, grants and 'soft' loans are recorded on the face value of the activity at the date a grant or loan agreement is signed with the recipient. Cancellations and reductions of previous years' agreements are not included in the database. This article reports bilateral assistance using the markers for all energy generation, including coal, oil and gas development. Energy efficiency projects are not readily captured by the DAC marker system, hence the total amounts reported for energy efficiency from bilateral sources may be somewhat of an underestimate.

We had hoped to provide data on funding from multilateral agencies using the same set of markers, but data were not available at the same level of detail. Data from multilateral institutions are reported in a simplified format using categories drawn from the approach used by the World Bank Group to classify energy projects. While energy efficiency data are reported, such projects present a particular challenge in their classification. For example, a transmission line project may be reported by some organizations either as an expansion of the grid or an improvement in efficiency.

To keep the analysis manageable, this article mainly includes projects over USD 1 million. This leads to the exclusion of many valuable projects aimed at building capacity, training, feasibility studies, planning, enabling activities and, in some cases, small projects aimed at reforming the market. These types of project are essential to filling the 'project pipeline' with high-quality projects. We estimate that approximately one-third of all projects may fall into this category, but we have made no attempt to estimate the level of funding for these activities. We have also grouped together approved loans and grants. While most projects are supported through loans (for example, in the case of bilateral projects, loans account for $83 \%$ of all projects), grants play a special role by reducing the risks associated with new technologies which may not otherwise be deployed. We have also excluded loan guarantees, make no attempt to account for leveraging - that is, the extent to which projects are co-funded with private sector funds - and have not attempted to reconcile disbursements against approved loans and grants. 


\title{
Annex B: Establishing public/private partnerships: ESCO market development in China and India
}

Page | 64 China

\begin{abstract}
Process
In the late 1980s and early 1990s, the Chinese government initiated two different sets of policies that contributed to the development of an ESCO market in China (EMC). ${ }^{45}$ Starting from zero, the ESCO market rose to over 60 full service ESCOs in 2006, then to over 300 ESCOs in 2009 , worth about USD 880 million. The Chinese example is probably one of the most successful adaptations of energy performance contracting in emerging economies. Is this success sustainable? Can it survive the abandonment of the policies? What conditions allowed the success to unfold?
\end{abstract}

The first set of policies (introduced in 1994-1995) focused on the development of three pilot ESCOs, which enabled the emergence of the first phase of the market, and was developed concurrently by the Chinese government and the World Bank. The second phase was aimed at SMEs, which indirectly triggered the ESCO market development. During 1996 and 1997 the Chinese government worked hand-in-hand with the World Bank and GEF to replicate energy performance contracting (EPC) in China. The China Energy Conservation Project provided support for the establishment of three new pilot ESCOs. The project included (i) USD 5 million GEF grant to support each company in the development of an initial project, and (ii) USD 21 million of International Bank for Reconstruction and Development (IBRD) loan funds lent to the companies at commercial rates with the ESCOs covering all foreign exchange and repayment risks, for scaling up their businesses.

The full-service Chinese ESCO model placed the ESCO in charge. The entire process - from financing, project development, monitoring and implementation - was handled by the ESCO. The two main sectors of ESCO market activity were the industrial and commercial buildings. ${ }^{46}$ Commercial building projects focus primarily on heating, ventilation and air conditioning (HVAC), system renovations and innovations, and lighting system renovation projects. Projects focus on fuel savings (especially direct savings in coal use) as well as electricity savings. The energy cost savings expected were calculated using current energy prices. The ESCOs were supposed to finance the project, and were paid from a large share of estimated initial energy cost savings.

\section{Achievements}

The ESCO development project met its goals: the three new ESCOs adapted energy performance contracting in a profitable way within the Chinese market, and created strong operational examples easily replicable by others within the country. By the end of 2006, the three ESCOs

\footnotetext{
${ }^{45}$ ESCOs in China are usually referred to as Energy Management Companies (EMCs).

${ }^{46}$ Industrial renovation projects are generally focused on equipment including, in particular, boiler renovations, technology upgrading in combustion systems, renovation of kilns and furnaces, waste heat or gas recovery and use, motor drive system renovations, cooling system replacements, internal power supply renovation, and introduction of automatic controls.
} 
had implemented about 350 energy performance contracting projects, with investments totalling about USD 170 million. The financial performance and profitability of all three companies were strong. ${ }^{47}$ The success of the first ESCOs led to the creation of others starting in 2000. The intervention of the government for both the second energy conservation projects with USD 26 million additional financing from GEF as well as through the SMEs financing might have contributed to this increased development. The second generation of energy conservation projects benefitted from the creation of EMC loan guarantee programme, which sought to expand and improve the first generation of conservation projects. Its aim was to gradually develop commercial lending to the EMCs banking sector, and improve risk sharing between guarantee companies and banks. It also included training, technical assistance and policy development support for emerging ESCOs through EMCA. ${ }^{48}$

Overall, the policies allowed the creation of a collaborative effort between local and international institutions. It allowed the creation of a collaborative effort between local and international institutions (GEF/World Bank and the Chinese government). Moreover, it contributed to capacity building in the Chinese market through the creation of EMCA - which meant that newcomers could also come for advice. ${ }^{49}$ Over three years of implementation through 2006, the China National Investment and Guarantee Company, I\&G, has issued a total of 85 ESCO loan guarantees, totalling USD 32.1 million. These guarantees have leveraged commercial loans from 11 different Chinese banks totalling USD 35.6 million $^{50}$ in support of EPC investment of USD 57.2 million. ${ }^{51}$ Loan guarantee support has been provided to 29 different ESCOs, which represents almost half of companies confirmed as implementing EPC projects in 2006. These ESCOs are located in 16 different provinces. Again government intervention was instrumental in allowing the success of these programmes.

\section{India}

\section{Process}

The Indian situation is very different from the Chinese context. Though the Chinese ESCO market totals around 300 ESCOs, the Indian market is still at the preliminary stages. The Ministry of Power estimates that only 5\% of Indian ESCO market potential has been tapped (WRI, 2010). In recent months, the Government of India (GOI) has reinforced its commitment towards promoting energy efficiency. Beyond the commitment to the Bureau of Energy Efficiency (BEE), which has seen its budget increase four-fold in four years, $\mathrm{GOI}$ committed to reinforce the EE market through the creation of a public/private company called the Energy

\footnotetext{
${ }^{47}$ Building renovation and boiler renovation/cogeneration were the most important areas of concentration of the main ESCOs from 2000 to 2006. The most common in terms of investment volume, both with about one quarter share. It is worth mentioning that the three EMCs concentrate on different sectors. Almost three quarters of the investments of the Beijing EMC are in building renovation (mostly HVAC), while the EMCs in Liaoning and Shandong invest much more heavily in the industrial sector with more than $60 \%$ of investments in boiler/cogeneration, kiln/furnace and waste heat/gas recovery (Taylor, 2008).

${ }^{48}$ The EMCA is the China ESCO Association of China that was created by the second generation of conservation projects as an institution of ESCO mutual support that would also provide technical assistance to newcomers.

${ }^{49}$ The programme seriously allowed the development of capacity and staff training. With no special prior experience in evaluating EE projects, I\&G engaged a technical advisor to work full time on technical review, and maintain contact with a small pool of individual external technical experts that it can call upon when needed. I\&G also utilises the informal technical advice of EMCA staff and others associated with the World Bank projects.

${ }^{50}$ CNY 274 million.

${ }^{51}$ CNY 440 million.
} 
Efficiency Services Ltd. (EESL). The EESL will be a joint venture company with equity participation of $25 \%$ each from its promoters: the National Thermal Power Corporation (NTPC), Power Grid Corporation of India Ltd. (PGCIL), the Rural Electrification Corporation Ltd. (REC) and the Power Finance Corporation (PFC). It will provide implementation leadership in the area of energy efficiency and undertake implementation of the EE scheme.

Page | 66 EESL aims to act as an exemplary energy service company for certain schemes, as a consultancy organisation for CDM projects for demand-side management and, in the industrial sector, as a resource centre for training and capacity building of utilities and other stakeholders. Its business model predicts an economic viability on a projected internal rate of return (IRR) of $22 \%{ }^{52}$ Although details of the entity's financing and management structure are yet to be defined, the $\mathrm{GOI}$ is making a commendable effort at using government money to promote resources towards the development of an Indian ESCO market. ${ }^{53}$

\section{Achievements}

Although starting, there is yet to be a real and active policy by the government for the development of ESCO market in India. According to the Minstry of Power, ${ }^{54}$ the investment potential for Indian EE market is huge: USD 9.8 billion with an annual potential savings of 183.5 billion $\mathrm{kWh}$ if tapped, it could amount to $\mathrm{CO}_{2}$ emission savings of $148.6 \mathrm{Mt}$ annually Developing the ESCO market entails government intervention to guarantee risk endured by ESCO - just as they would a customer's to ensure the capital provider's willingness to finance the project. The recent government decision to accredit ESCOs through BEE could be a step in the right direction.

New government provision is already meeting with some success. The growth of this industry has led to investor interest in funding the EE sector. In 2007, ICICl Bank, India's second largest commercial bank, provided USD 1.25 million in debt funding to HMX Sumaya, a New Ventures India finalist company that manufactures energy efficient HVAC systems. In 2008, Tribi Embedded Technologies, another New Ventures India finalist company, received USD 2.5 million in equity funding from Sequoia Capital, an international venture capital firm with close to 60 investments and USD 1.8 billion capital under management in India.

\section{Lessons and limits}

Both Indian and Chinese examples of ESCO market development underline the importance of government intervention in creating enabling environments and triggering private investments. Although the creation of the ESCO market did not directly mitigate risk - which is merely transferred from customers to ESCOs - government intervention enabled indirect training and familiarisation of private actors to EE financing. As such, ESCOs usually meet with the same difficulty in getting access to capital. Lacking sufficient levels of equity, as well as an absence of

\footnotetext{
52 See E-Gov, August 2009: information was given by Shri Bharatsinh Solanki, Minister of State, Ministry of Power in a written reply to a question by Shri Dharam Pal Sabharwal in the Rajya Sabha; the government further informed that the equity of EESL will be RS. 190 crores (equivalent to about USD 30 million) with equal contribution from NTPC, PFC, REC and Powergrid. This should enable the company to leverage an estimated Rs. 700-800 crores (USD 90-120 million)

${ }^{53}$ This effort should facilitate private-sector involvement in the EE market. This effort towards the creation of EESL goes hand-in-hand with the previous government effort to start white certificate trading in India. Although it is too early to measure the impact of such effort, the GOl's move towards establishing certification, commitment and trading capacity through the PFC has already enhanced private sector awareness and interest in EE projects.

${ }^{54}$ www.adb.org/Documents/events/2008/ACEF/Session17-Natarajan.pdf
} 
significant track records, ESCOs have difficulty convincing investors that they are safe investments. Measures such as BEE accreditation further reassured investors and reduced risk perception. China went one step further by allowing the IFC to provide a risk guarantee programme for local commercial banks financing EE projects.

Despite these successful results, the policies were not a silver bullet. The second generation of policies in China did not support training of bank staff, but rather let them rely on intermediaries, namely the ESCOs. The policies have not yet designed a solution for dealing with capital issue of ESCOs. ${ }^{55}$ The insurance and brokers company (I\&G) did everything; no training was provided for private, local ESCOs and banks. In that case then I\&G had control over the process from start to finish. As such there is no guarantee that the programme will go on if the policy is abandoned.

The very low equity levels and the absence of track records of new ESCOs makes ESCO financing as challenging as customers' ${ }^{56}$ As a Hong Kong investor pointed out, private financiers are still wary of investing in ESCOs, and clients are finding it difficult to absorb the idea of investing in an intangible product. There is still a general lack of trust among the private financial community towards the small ESCOs. ${ }^{57}$ Someone from the BEE underlined that, for the time being, Indian banks were not ready to finance ESCOs. As such, government should strive to provide risk guarantee mechanisms to complement ESCO market development measures.

\footnotetext{
${ }^{55}$ As mentioned in section 1 of the study, ESCO's are finding it very difficult to raise equity. This is particularly the case when the market is emerging since they have no track record of projects to show to the investors. The particular structure of an EE project - i.e. which does not provide many options for exit strategies such as Initial Public Offerings (IPOs) - further discourages investors to take equity stakes in the company. Again, this reinforces the notion that project finance structures are more adapted to ESCO financing. However these will not cover the incremental upfront costs of the projects, which will, in turn, be a problem for least developed and poorest countries.

${ }^{56}$ Interviews with local banks, as well as ESCO developers in India typically indicated that the most important deterrent in ESCO's quest for credit was ESCO's absent track records and the credibility gap which it created. High equity or capital can make up for an absent track record, however ESCOs most commonly lack sufficient equity to make up for it (Sturn, 2006; Roy, 2008); Personal conversation with different ESCO managers in India and China.

${ }^{57}$ Those that are not Johnson Control or Honeywell.
} 


\section{Annex C: Questionnaire sent to banks and participating institutions}

Page | 68 The purpose of the questionnaire was to determine: (i) the level of knowledge and subsequent actions that the financial institutions have on climate change negotiations and carbon markets; (ii) the level of knowledge and subsequent actions (including level of investments) in energy efficiency; (iii) what has influenced them most in that course of action (policy, customer demand, strategic thinking, evolution of regulation, fear of more stringent regulation); (iv) the general functioning of the bank including criteria for decision making on investments, etc.

Institutions interviewed include:

Aequero, Deutsche Bank, JP Morgan, Morgan Stanley, Climate Change Capital, Yes Bank, IFC, World Bank, ICICl, Marsh, New Energy Finance, EIB, ESCO Managers. 


\section{Name of the institution: TB}

Field of activity: TBI

Name/Responsibility of person answering questionnaire: TBI

(i) Knowledge of climate change/ Influence on activities

1- What do you know about climate change negotiations?

2- What is your understanding of carbon markets?

3- In your view, what is the impact - if any - of the carbon markets on your business?

4- Is carbon footprint a factor in your investment decisions? If so, how so?

5- By reference to the previous question would you consider your institution takes climate change issues into account in its financing/investments decisions in any way?

6- What would be the impact of the creation of a new cap-and-trade market (i.e. in the US or other) on your activities?

7- How much money does your institution spend on financing clean development mechanism (CDM) projects? Are these investments considered successful? Could you name a recurring problem that you have encountered in putting them in place?

8- How important are India and China in your investment portfolio?

9- What proportion of the energy portfolio does environmentally friendly investment represent?

10- Does your institution have a dedicated carbon finance team?

11- What/Where lies the future of the carbon trading for you?

12- What do you wish for future climate change negotiations?

(ii) Knowledge of Energy Efficiency (EE) and actions

13- What is your understanding of energy efficiency? Please explain.

14- Do you have any targeted financing instrument for EE projects? If no, why (and do you have some for renewable projects?). If yes, what pushed you towards such action?

15- What do you perceive as the highest obstacle to your institution financing more EEprojects?

16- Do you have any experience of successful EE financing? At a large scale? At an individual scale?

17- What amount of EE investment does your institution commit to each year? Is that amount actually distributed? If not what is usually the difference between the amount committed and the amount disbursed? An estimate would be acceptable here, but please specify which investments are actually considered (i.e. project financing, individual customer loans, M\&A in energy efficient appliances manufacturer or other)?

18- What is the ratio of energy efficiency investments compared to the overall energy portfolio?

19- Would you consider formally committing to increase EE investments? What would you consider doing?

20- What is the future of EE financing within your institution?

21- Does your institution have a micro-finance unit?

22- Does your institution have a dedicated EE team? If so; how many people does it constitute?

(iii) Influencing factors in decision making process

23- What pushed towards the creation of carbon finance unit?

24- Did the fear of increased regulation influence that decision?

25- What could push you towards increased innovation in energy efficiency financing instruments?

(iv) Definition of success for new instruments and general functioning of institution

26- What ROI ratio is worth your investment?

27- What specific measures have been put in place in your institution to help tackle climate change issues (i.e. special unit, criteria, other)

28- What do you do to influence your clients in considering other public good (climate change)? If so in which ways?

29- Would you welcome the inclusion of the banking sector in the EU ETS (i.e. making banks responsible for the projects in which they invest)?

30- Alternatively, would you consider joining a trans-national sectoral initiative which commits to reducing carbon footprints to a fixed target? What if the target was not fixed? What if there were financial punishments in case of non-compliance, but that all the banks were under the same constraints, would that be easier? 



\section{iea}

\section{International Energy Agency}
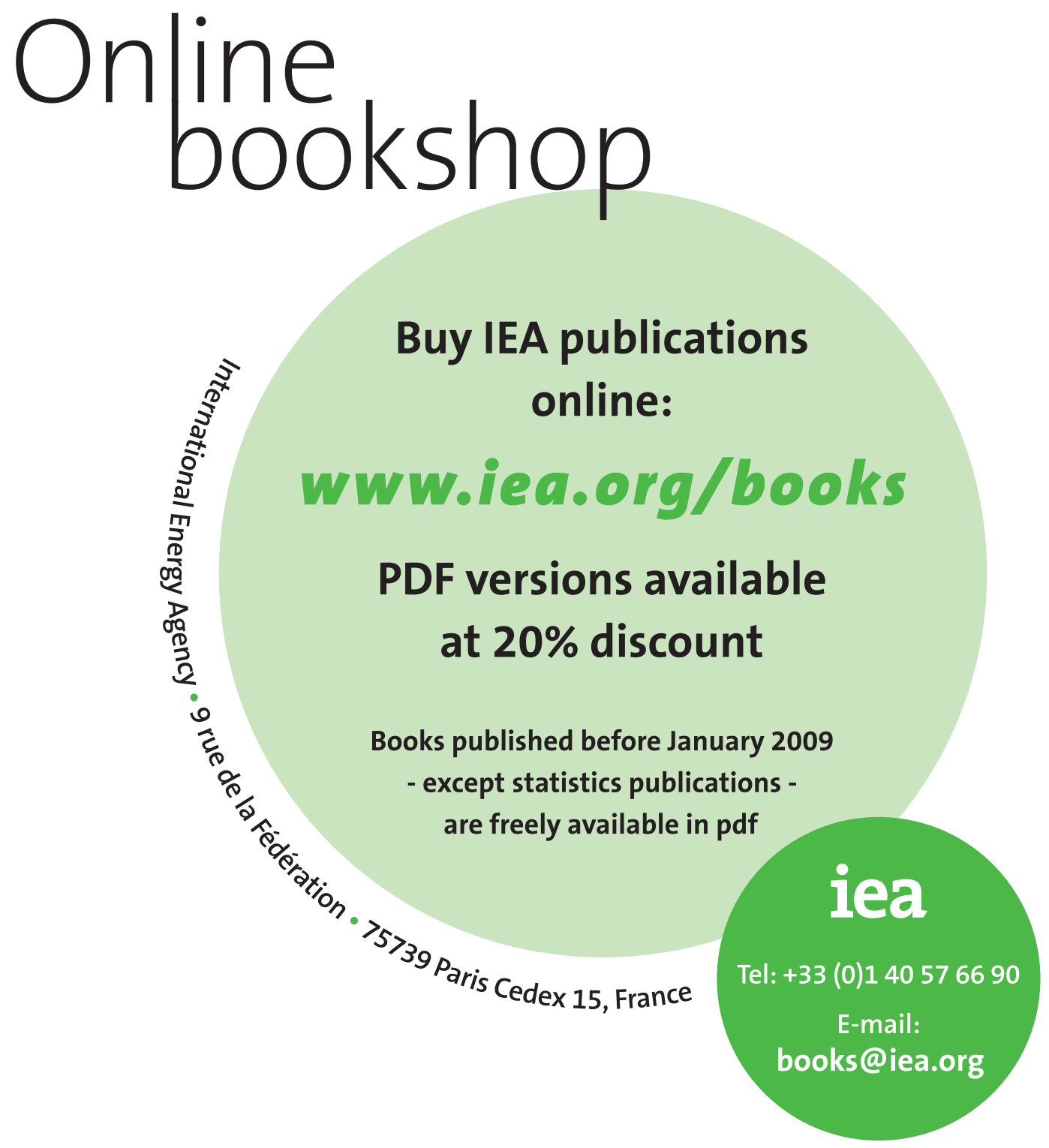


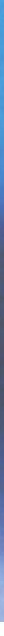

9 rue de la Fédération 75739 Paris Cedex 15

www.iea.org 